\title{
Supplement to "A new model mechanism for atmospheric oxidation of isoprene: global effects on oxidants, nitrogen oxides, organic products, and secondary organic aerosol"
}

\author{
Kelvin H. Bates ${ }^{* 1}$ and Daniel J. Jacob ${ }^{2}$ \\ ${ }^{1}$ Faculty of Arts and Sciences, Harvard University, Cambridge, MA 02138, USA \\ ${ }^{2}$ School of Engineering and Applied Sciences, Harvard University, Cambridge, MA 02138, \\ USA
}

March 19, 2019

*for correspondence: kelvin_bates@fas.harvard.edu

\section{Contents}

S1 Additional details from global simulations $\quad$ S2

S2 Light \& temperature sensitivities in fixed-radical box models $\quad$ S6

S3 Emission sensitivities in global models $\quad$ S11

$\begin{array}{ll}\text { S4 Isoprene oxidation at night } & \text { S12 }\end{array}$

S5 Comparisons to other mechanisms $\quad \mathbf{S 1 5}$

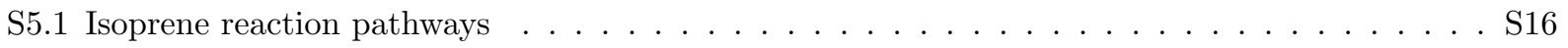

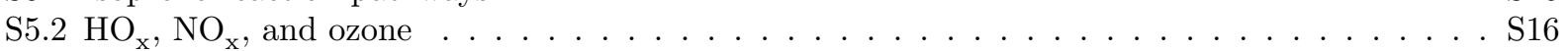

S5.3 Organic products . . . . . . . . . . . . . . . . . . . . S S21

$\begin{array}{lr}\text { S6 Mechanism simplification } & \text { S28 }\end{array}$ 


\section{S1 Additional details from global simulations}

Tables S1-S3 provide additional details from global simulations of RCIM. Tables S1-S2 show the percent changes in global annual average tropospheric burdens of compounds of interest between a standard global simulation and a perturbed simulation. Perturbations include removing isoprene chemistry altogether, using the GEOS-Chem v11-02c mechanism, and using the RCIM with different ISOPOO isomer branchings. Table $\mathrm{S} 1$ also shows changes due to the removal of specific isoprene and ISOPOO reaction pathways (e.g. isoprene $+\mathrm{O}_{3}$ or ISOPOO $+\mathrm{RO}_{2}$ ), which gives a sense of the specific contributions of these pathways to the overall tropospheric effects of isoprene oxidation. Table $\mathrm{S} 2$ shows similar perturbations but with specific oxidation products (e.g. MVK, IEPOX) removed, which gives a sense of those products' contributions to isoprene's tropospheric effects, as well as perturbations to isoprene nitrate chemistry. Table S3 provides global annual average molar yields of VOCs from isoprene, using both RCIM and GEOS-Chem v11-02c, as well regional molar yields in the Southeast United States, the Amazon, and East China using RCIM. 


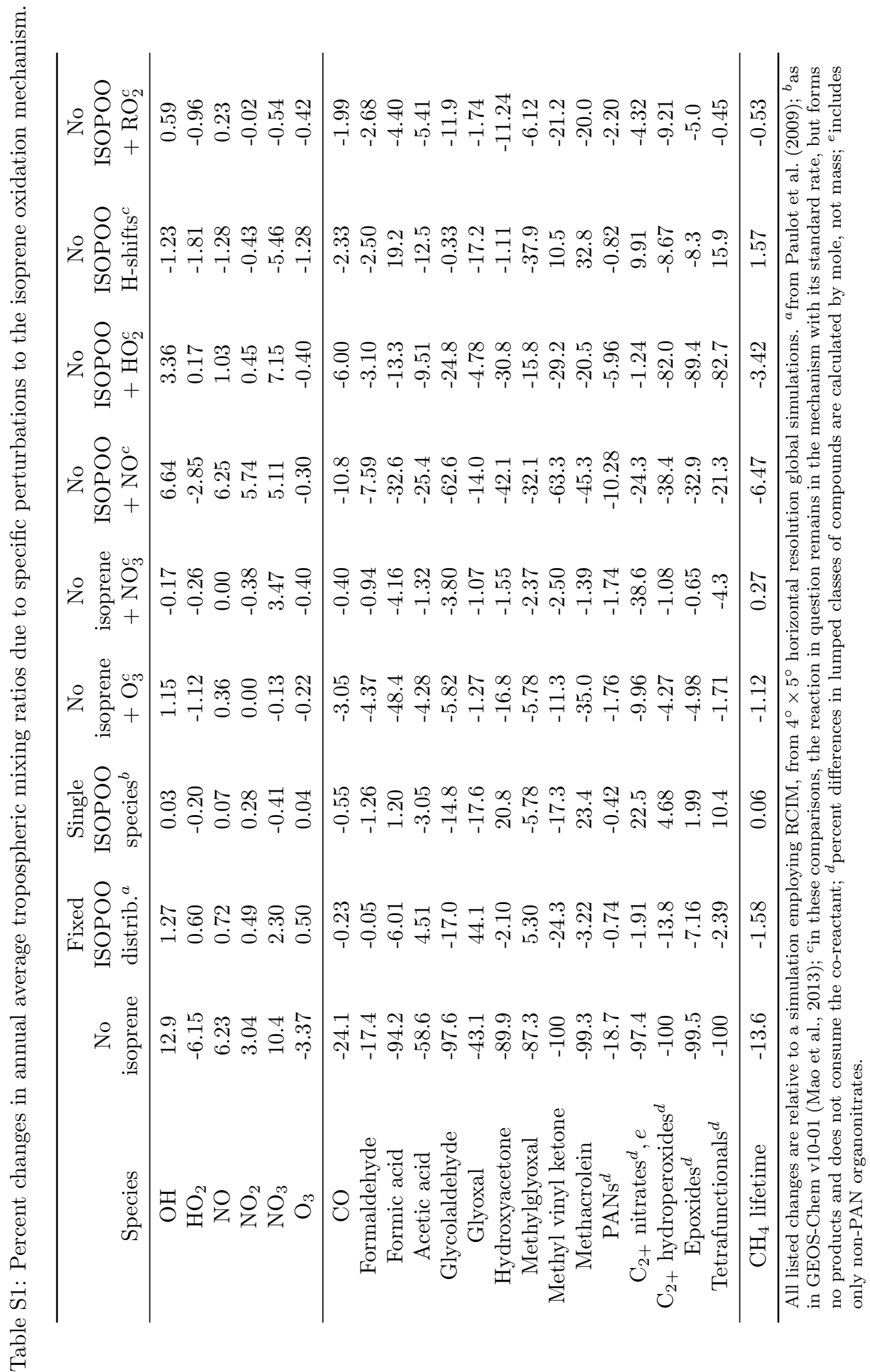




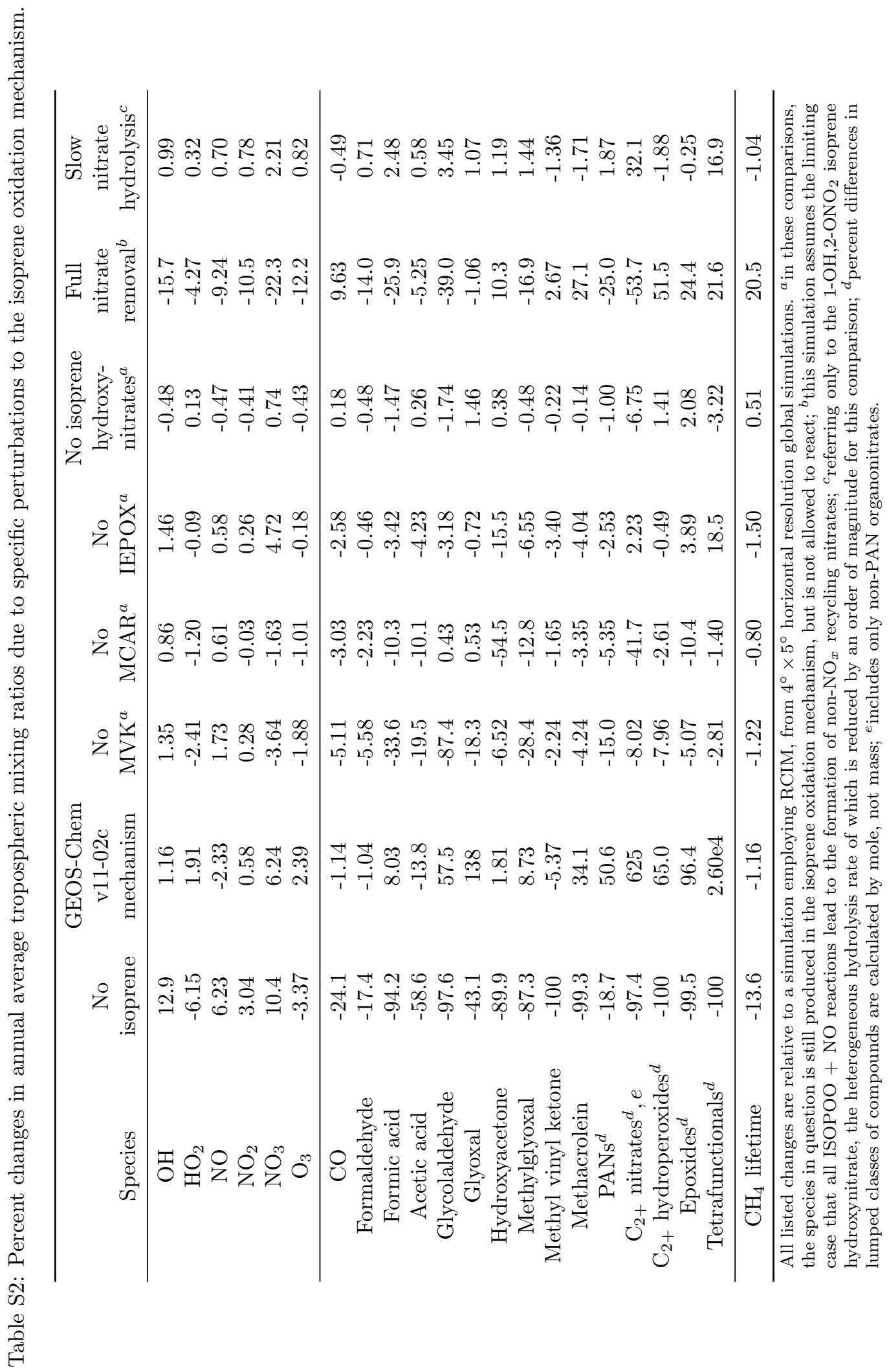


Table S3: Molar yields of VOCs and SOA precursors of interest from isoprene ${ }^{a}$

\begin{tabular}{|c|c|c|c|c|c|}
\hline Species & Global & Global, v11 ${ }^{b}$ & SE USA & Amazon & E China \\
\hline $\mathrm{CO}$ & 190 & 180 & 150 & 138 & 213 \\
\hline Formaldehyde & 111 & 107 & 97.7 & 79.4 & 148 \\
\hline Formic acid & 5.76 & 6.33 & 5.28 & 4.12 & 7.59 \\
\hline Acetic acid & 5.49 & 4.18 & 2.93 & 3.34 & 4.59 \\
\hline Hydroxymethyl hydroperoxide & 3.94 & - & 4.55 & 4.71 & 2.53 \\
\hline Glycolaldehyde & 11.5 & 16.2 & 11.1 & 5.00 & 23.7 \\
\hline Glyoxal & 1.63 & 5.47 & 1.06 & 1.08 & 2.06 \\
\hline Hydroxyacetone & 12.3 & 11.1 & 10.6 & 7.72 & 15.2 \\
\hline Methylglyoxal & 20.1 & 24.5 & 16.1 & 13.4 & 25.3 \\
\hline Methyl vinyl ketone & 27.9 & 21.5 & 31.1 & 22.0 & 42.2 \\
\hline Methacrolein & 15.9 & 17.3 & 17.9 & 15.1 & 21.3 \\
\hline $\mathrm{C}_{4}$ dihydroxycarbonyls & 6.32 & 3.67 & 4.99 & 3.59 & 4.58 \\
\hline $\mathrm{C}_{4}$ hydroxydicarbonyls & 10.6 & - & 7.60 & 6.49 & 8.43 \\
\hline $\mathrm{C}_{2+}$ nitrates $^{c, d}$ & 5.99 & 6.96 & 9.08 & 1.30 & 15.1 \\
\hline $\mathrm{C}_{5}$ nitrates ${ }^{c}$ & 4.82 & 4.79 & 7.55 & 1.02 & 11.8 \\
\hline $\mathrm{C}_{5}$ hydroxynitrates & 3.60 & 2.61 & 5.31 & 0.782 & 9.25 \\
\hline $\mathrm{C}_{4}$ nitrates $^{c}$ & 0.878 & 1.70 & 1.10 & 0.234 & 2.42 \\
\hline Propanone nitrate & 0.188 & 0.412 & 0.304 & 0.0277 & 0.627 \\
\hline $\mathrm{C}_{2+}$ hydroperoxides ${ }^{c}$ & 52.3 & 42.6 & 43.9 & 58.7 & 24.9 \\
\hline ISOPOOH & 35.3 & 33.8 & 29.7 & 41.2 & 14.0 \\
\hline $\mathrm{C}_{5}$ hydroperoxy aldehydes & 6.77 & 5.80 & 4.93 & 8.49 & 3.42 \\
\hline Epoxides $^{c}$ & 25.7 & 25.8 & 23.3 & 20.9 & 15.3 \\
\hline IEPOX & 20.1 & 19.9 & 18.3 & 17.1 & 9.84 \\
\hline HMML & 0.732 & 5.85 & 0.937 & 0.154 & 2.42 \\
\hline Tetrafunctionals ${ }^{c}$ & 4.07 & 4.11 & 3.73 & 3.26 & 2.63 \\
\hline $\mathrm{IDHPE}^{e}$ & 2.20 & - & 1.86 & 2.12 & 0.847 \\
\hline $\mathrm{IDHDP}^{f}$ & 0.530 & 0.0992 & 0.438 & 0.486 & 0.159 \\
\hline $\mathrm{ICPDH}^{g}$ & 0.458 & 0.584 & 0.346 & 0.380 & 0.185 \\
\hline $\mathrm{IDCHP}^{h}$ & 0.384 & - & 0.349 & 0.190 & 0.359 \\
\hline $\mathrm{ICHNP}^{i}$ & 0.232 & - & 0.319 & 0.0353 & 0.479 \\
\hline $\mathrm{IDHPN}^{j}$ & 0.218 & 0.466 & 0.348 & 0.0386 & 0.411 \\
\hline
\end{tabular}

${ }^{a}$ Results from $2^{\circ} \times 2.5^{\circ}$ horizontal resolution global simulations using RCIM. Yields of species with additional non-isoprene precursors are calculated by taking the difference in production between a simulation with isoprene and one without isoprene emissions. Yields of $\mathrm{CO}$ and formaldehyde calculated with this method are then corrected for differences in total methane oxidation between the simulations. ${ }^{b}$ Using the GEOS-Chem v11-02c mechanism instead of RCIM. ${ }^{c}$ Yields of lumped species may include multiple generations of a single oxidation pathway (e.g., separately counting both IEPOX and its oxidation product, isoprene hydroxycarbonyl epoxides). ${ }^{d}$ Includes only non-PAN organonitrates. ${ }^{e} \mathrm{C}_{5}$ dihydroxy-hydroperoxy-epoxides. ${ }^{f} \mathrm{C}_{5}$ dihydroxy-dihydroperoxides. ${ }^{g} \mathrm{C}_{5}$ dihydroxy-carbonylhydroperoxides. ${ }^{h} \mathrm{C}_{5}$ dicarbonyl-hydroxy-hydroperoxides. ${ }^{i} \mathrm{C}_{5}$ carbonyl-hydroxy-hydroperoxy-nitrates. ${ }^{j} \mathrm{C}_{5}$ dihydroxy-hydroperoxy-nitrates. 


\section{S2 Light \& temperature sensitivities in fixed-radical box models}

Figures S1-S5 show the effects of varying light and temperature on $\mathrm{HO}_{x}$, ozone, oxidation pathways, and VOC yields in fixed-radical box models. In addition to the simulations described in the main text, the model was run with every permutation of (a) temperature set to $283.15 \mathrm{~K}, 298.15 \mathrm{~K}$, and $313.15 \mathrm{~K}$, and (b) solar radiation for photolysis set to clear-sky equatorial midday with an ozone column of $350 \mathrm{DU}, 0.1 \times$ equatorial midday, and 0 . The primary effect of temperature is to increase the rates of $\mathrm{H}$-shift reactions, which substantially increases their relative contribution to the fate of the ISOPOO radicals (Figure S1). This leads to an increase in overall net $\mathrm{HO}_{x}$ recycling from isoprene oxidation (Figure $\mathrm{S} 2$ ). Increased photolysis rates from higher photon fluxes also lead to increased net $\mathrm{HO}_{x}$ recycling (Figure S2) and net potential ozone production (Figure S3) from isoprene oxidation.

The effects of temperature on VOC yields (Figure S4) are largely mediated by the temperature dependence of H-shift reactions (Peeters and Nguyen, 2012; Peeters et al., 2014; Crounse et al., 2011; Praske et al., 2018) and of nitrate formation branching ratios in reactions of peroxy radicals with NO (Arey et al., 2001; Carter and Atkinson, 1985, 1989). Thus, overall yields from isoprene of ISOPOO H-shift products (e.g. $\mathrm{C}_{2}$ - $\mathrm{C}_{5}$ hydroperoxyaldehydes) increase with temperature, while those of organonitrates decrease. The effects of light on VOC yields (Figure S5) are generally smaller than those of temperature, but among the most pronounced are a decrease in formaldehyde yields and an increase in methylglyoxal yields under low-light conditions.

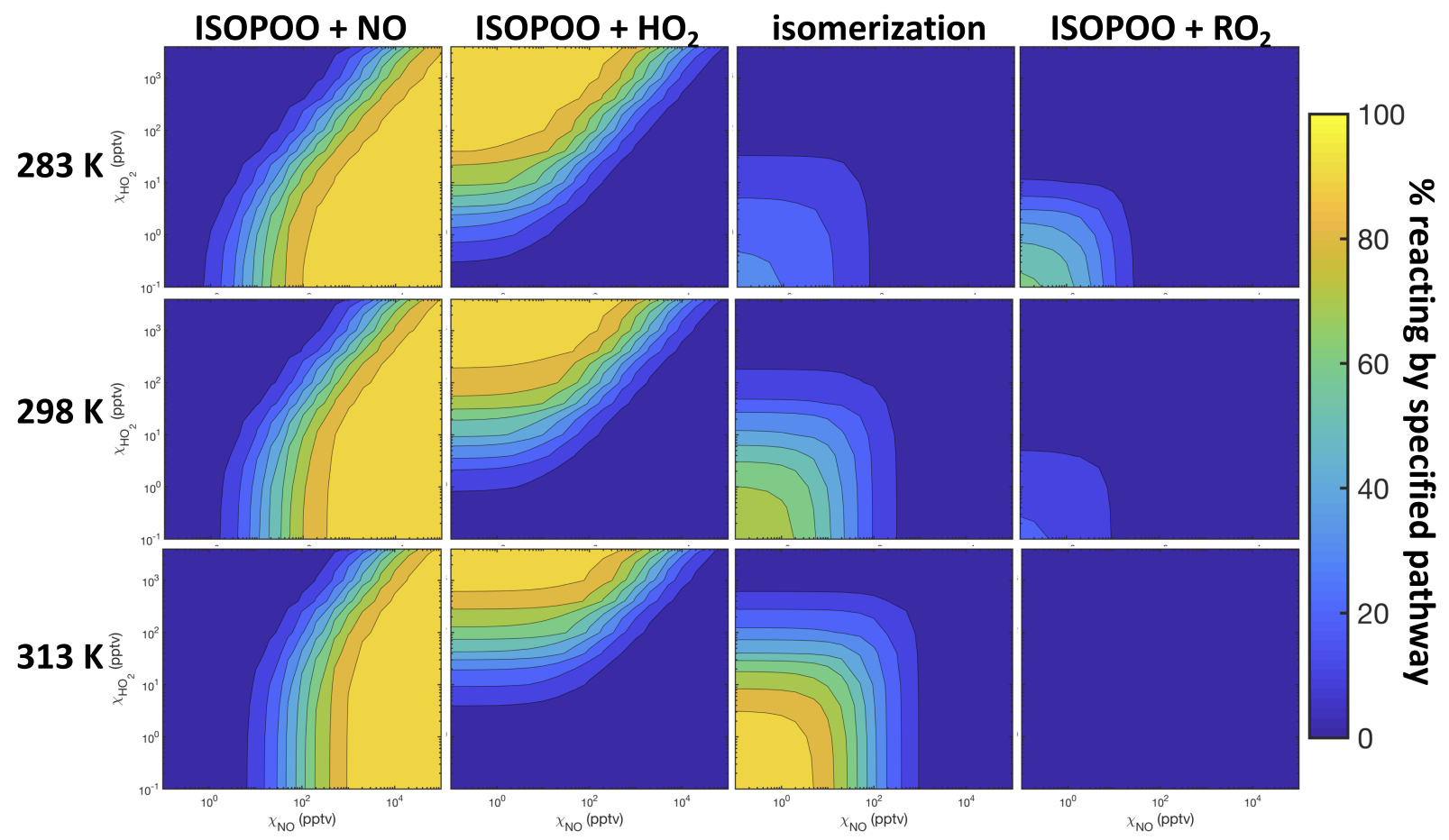

Figure S1: Temperature dependence of the percent of isoprene hydroxy peroxy radicals reacting via each pathway as a function of $\mathrm{NO}$ and $\mathrm{HO}_{2}$, from fixed-radical box modeling of RCIM. 


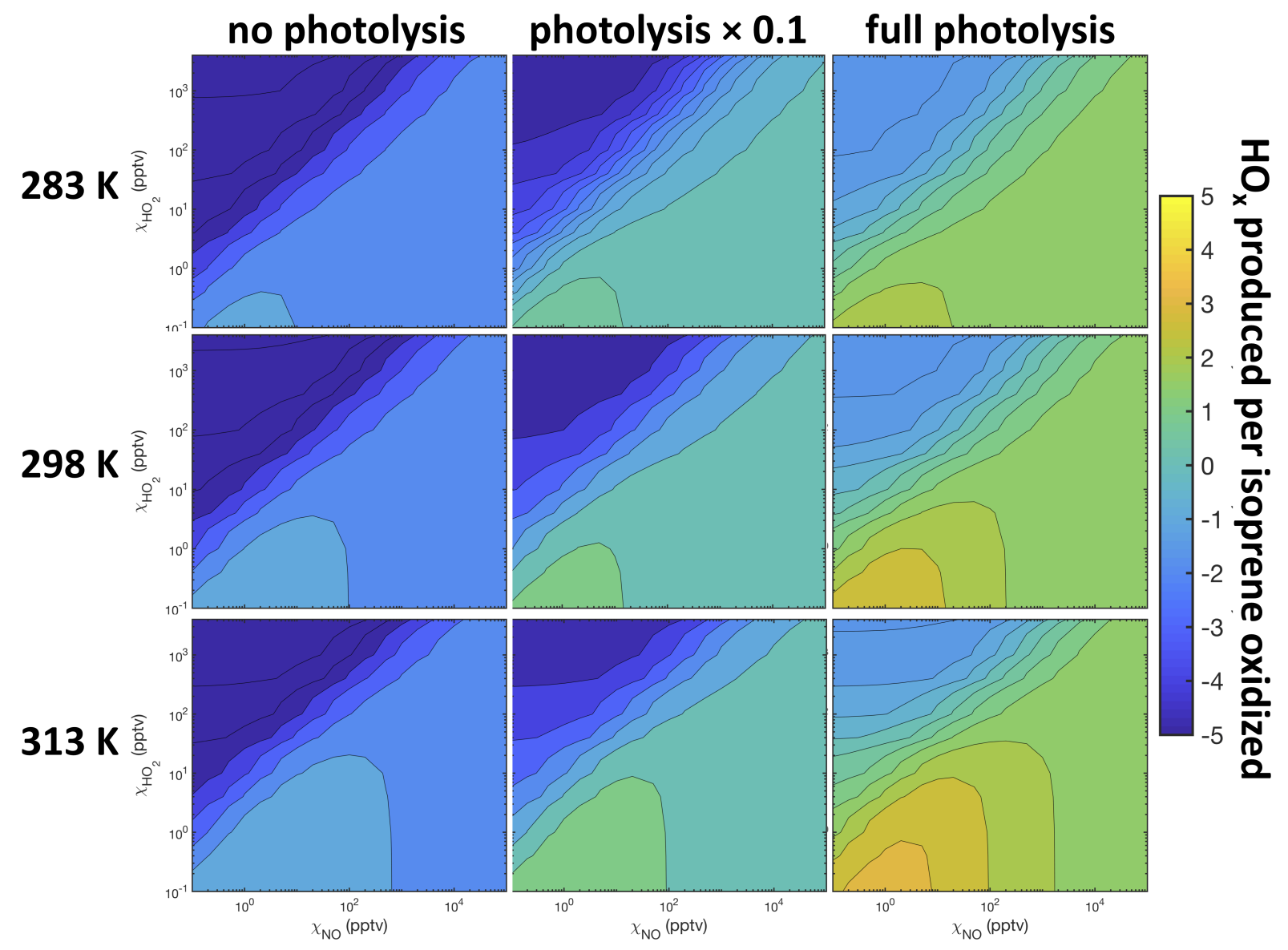

Figure S2: Net effects of isoprene oxidation on $\mathrm{HO}_{\mathrm{x}}$ under various temperature and light conditions as a function of $\mathrm{NO}$ and $\mathrm{HO}_{2}$, from fixed-radical box modeling of RCIM. 


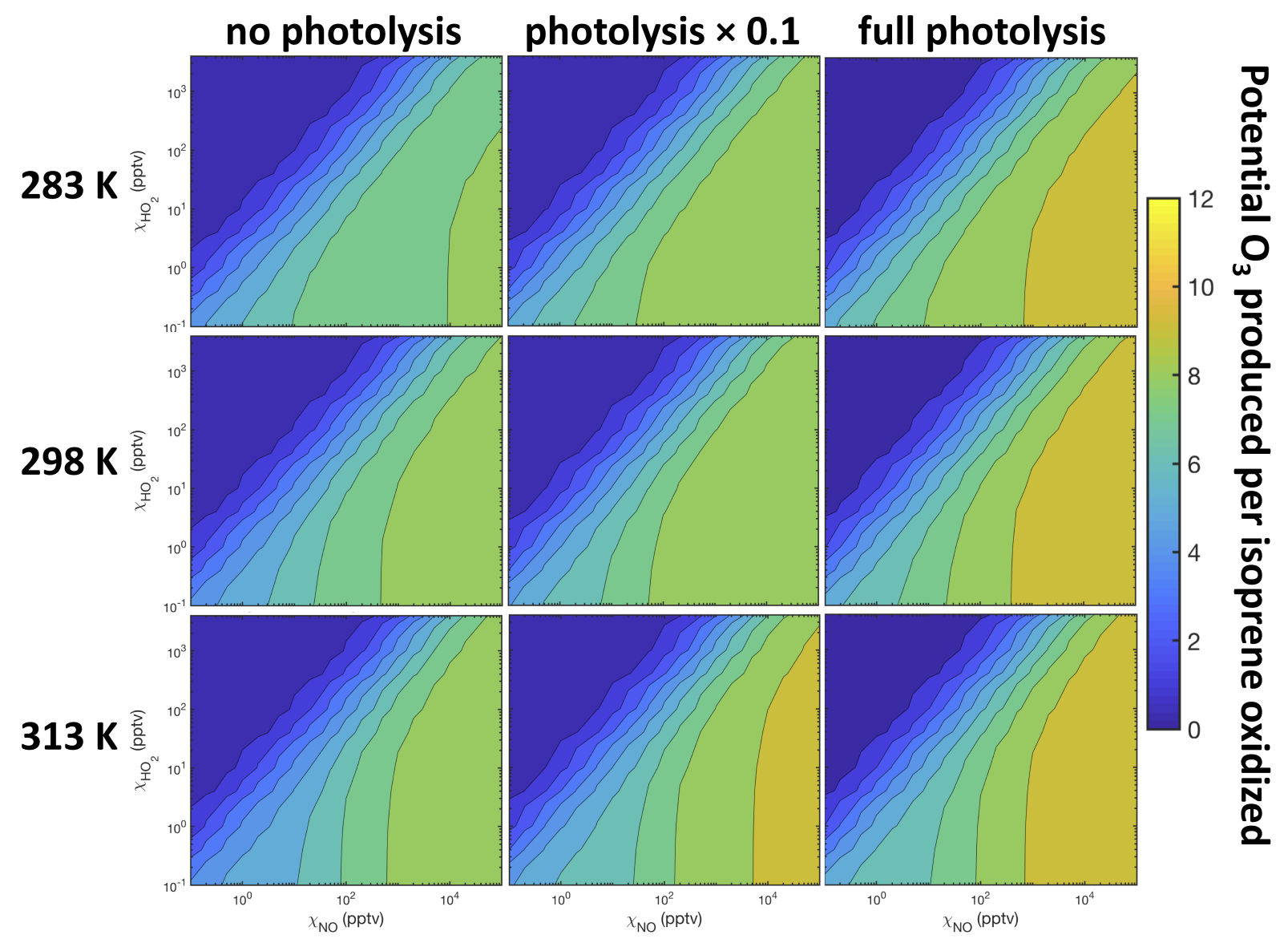

Figure S3: Net effects of isoprene oxidation on potential $\mathrm{O}_{3}$ - estimated as the sum of the ozone, $\mathrm{NO}_{2}$, and $\mathrm{HO}_{2}$ (times the fraction of $\mathrm{HO}_{2}$ that would go on to react with $\mathrm{NO}$ ) produced over the course of its oxidation - under various temperature and light conditions as a function of $\mathrm{NO}$ and $\mathrm{HO}_{2}$, from fixed-radical box modeling of RCIM. 


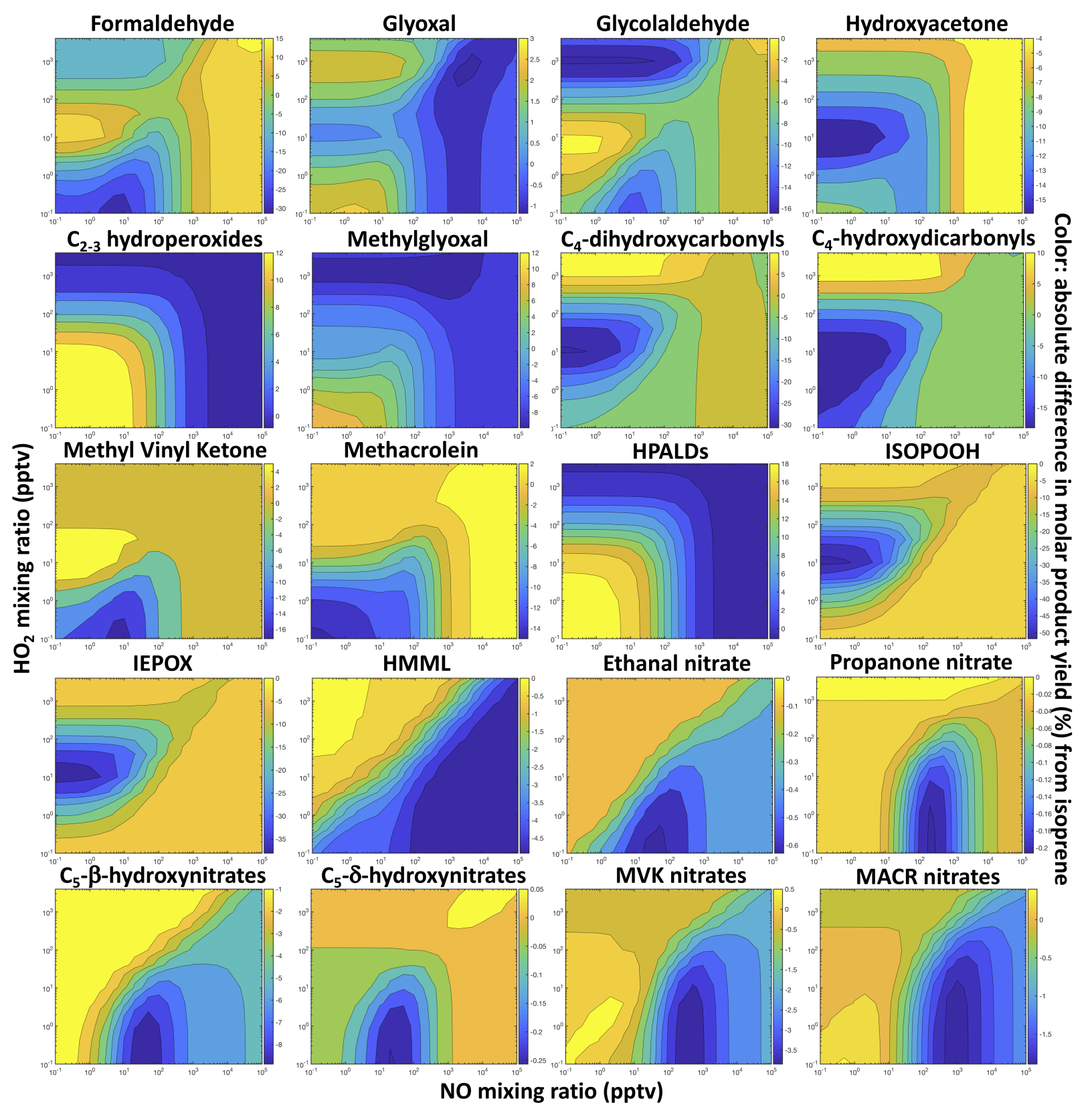

Figure S4: Absolute changes in percent yields of compounds of interest from isoprene when switching from fixed-radical box models fun at $10{ }^{\circ} \mathrm{C}$ to simulations run at $40{ }^{\circ} \mathrm{C}$. All box models are run with full photolytic sunlight flux (equatorial midday) and using RCIM. 


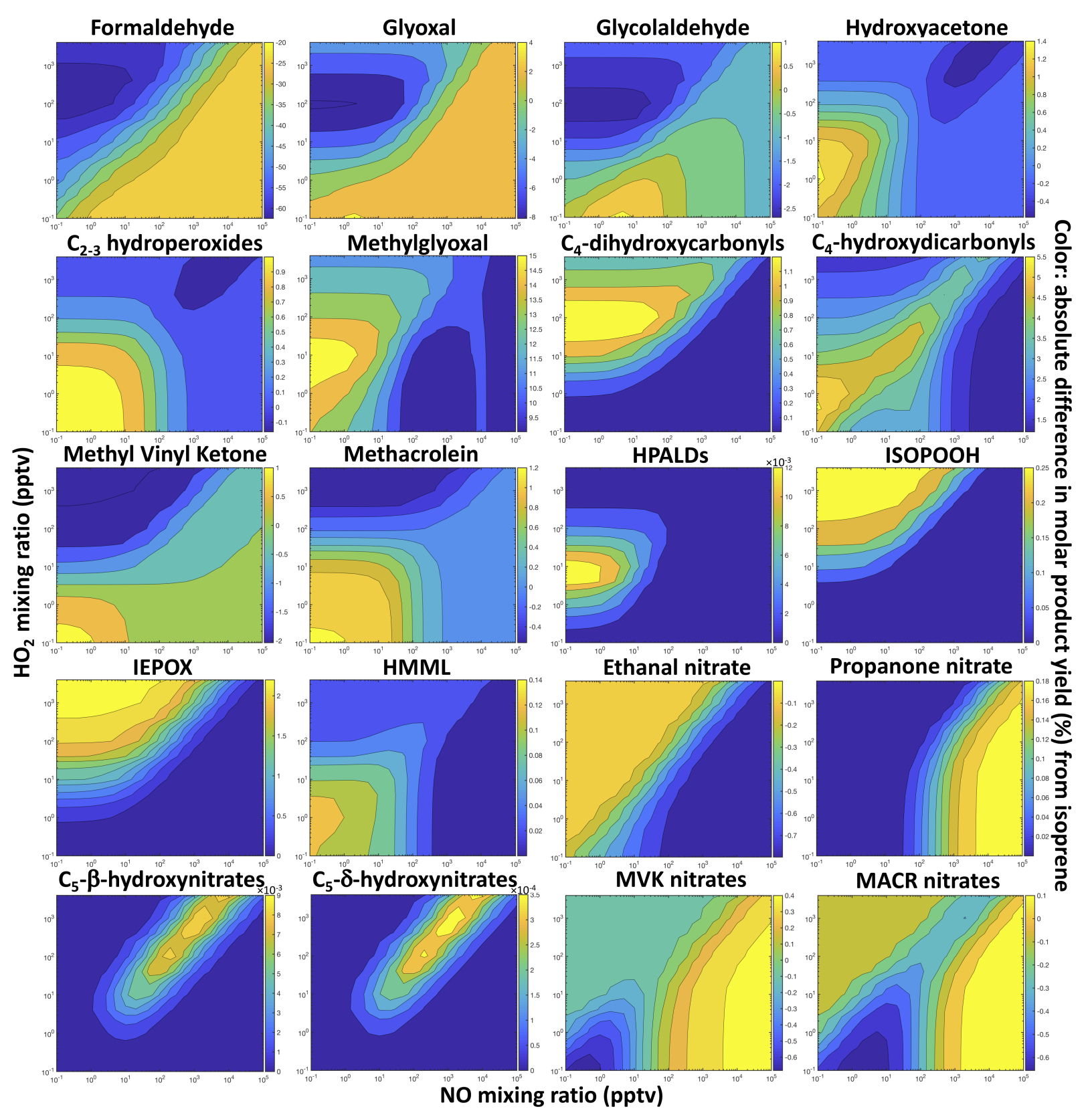

Figure S5: Absolute changes in percent yields of compounds of interest from isoprene when switching from fixed-radical box models with full photolytic sunlight flux (equatorial midday) to simulations with no photolytic light flux. All box models are run at $25^{\circ} \mathrm{C}$ and using RCIM. 


\section{S3 Emission sensitivities in global models}

Sensitivity simulations were performed with $10 \%$ increases and decreases to both isoprene and $\mathrm{NO}_{x}$ emissions worldwide, to examine the effects of these perturbations on the results reported herein. Changes in isoprene oxidation pathways due to emission changes can be found in Table S4, while changes in tropospheric average mixing ratios of species of interest can be found in Table S5. The contributions of isoprene oxidation pathways - including the initial oxidants, the ISOPOO fate, and the ISOPOO isomer reactivity - are largely insensitive to $10 \%$ perturbations in either $\mathrm{NO}_{x}$ or isoprene emissions, with the largest relative changes in the fraction of isoprene reacting with $\mathrm{NO}_{3}$.

Table S4: Global contributions of isoprene oxidation pathways with changed isoprene and $\mathrm{NO}_{\mathrm{x}}$ emissions. ${ }^{a}$

\begin{tabular}{cccccccc}
\hline \multirow{2}{c}{ Pathway } & $\begin{array}{c}\text { isoprene } \\
+10 \%\end{array}$ & $\begin{array}{c}\text { isoprene } \\
-10 \%\end{array}$ & $\begin{array}{c}\mathrm{NO}_{\mathrm{x}} \\
+10 \%\end{array}$ & $\begin{array}{c}\mathrm{NO}_{\mathrm{x}} \\
-10 \%\end{array}$ & $\begin{array}{c}\text { no anthro- } \\
\text { pogenic } \mathrm{NO}_{\mathrm{x}}\end{array}$ & $\begin{array}{c}\text { no anthrop. } \\
\text { or } \mathrm{BB} \mathrm{NO}_{\mathrm{x}}\end{array}$ \\
\hline \multirow{3}{*}{ isop +} & $\mathrm{OH}$ & 87 & 88 & 88 & 88 & 89 & 90 \\
& $\mathrm{O}_{3}$ & 11 & 10 & 10 & 10 & 10 & 10 \\
& $\mathrm{NO}_{3}$ & 1.7 & 1.8 & 1.8 & 1.7 & 0.9 & 0.5 \\
\hline \multirow{5}{*}{$\mathrm{RO}_{2}{ }^{b}+$} & $\mathrm{HO}_{2}$ & 42 & 41 & 41 & 41 & 45 & 47 \\
& $\mathrm{NO}$ & 27 & 29 & 29 & 27 & 18 & 13 \\
& $\mathrm{RO}$ & 8.8 & 8.2 & 8.5 & 8.6 & 11 & 13 \\
& $\mathrm{H}-\mathrm{shift}$ & 22 & 22 & 22 & 23 & 26 & 28 \\
\hline \multirow{5}{*}{ isomer } & $E / Z-1-\mathrm{OH}-\delta$ & 6.5 & 6.5 & 6.4 & 6.5 & 7.5 & 8.0 \\
& $1-\mathrm{OH}-\beta$ & 59 & 59 & 59 & 59 & 58 & 58 \\
& $E / Z-4-\mathrm{OH}-\delta$ & 14 & 14 & 14 & 14 & 16 & 16 \\
& $4-\mathrm{OH}-\beta$ & 21 & 21 & 21 & 21 & 19 & 18 \\
\hline
\end{tabular}

${ }^{a}$ Reported percentages are global tropospheric annual averages, from $4^{\circ} \times 5^{\circ}$ horizontal resolution GEOSChem simulations using RCIM; numbers may not add to $100 \%$ due to rounding; ${ }^{b}$ Referring only to the $\mathrm{RO}_{2}$ radicals formed in the reaction of isoprene with $\mathrm{OH}$ and $\mathrm{O}_{2}$. 
Table S5: Changes in tropospheric burdens due to perturbations to isoprene and $\mathrm{NO}_{\mathrm{x}}$ emissions $(\%)^{a}$

\begin{tabular}{ccccccc}
\hline Species & $\begin{array}{c}\text { isoprene } \\
+10 \%\end{array}$ & $\begin{array}{c}\text { isoprene } \\
-10 \%\end{array}$ & $\begin{array}{c}\mathrm{NO}_{\mathrm{x}} \\
+10 \%^{b}\end{array}$ & $\begin{array}{c}\mathrm{NO}_{\mathrm{x}} \\
-10 \%^{b}\end{array}$ & $\begin{array}{c}\text { no anthro- } \\
\text { pogenic } \mathrm{NO}_{\mathrm{x}}{ }^{b}\end{array}$ & $\begin{array}{c}\text { no anthrop. } \\
\text { or } \mathrm{BB} \mathrm{NO}_{\mathrm{x}}{ }^{b}\end{array}$ \\
\hline $\mathrm{OH}$ & -0.42 & 0.82 & $1.6(1.0)$ & $-1.3(-1.8)$ & $-4.5(-4.0)$ & $-0.12(0.86)$ \\
$\mathrm{HO}$ & 0.32 & -0.40 & $0.18(0.50)$ & $-0.27(0.06)$ & $-10(-9.3)$ & $-15(-14)$ \\
$\mathrm{NO}$ & -0.27 & 0.41 & $2.8(3.2)$ & $-2.5(-2.2)$ & $-17(-17)$ & $-20(-20)$ \\
$\mathrm{NO}_{2}$ & -0.21 & 0.13 & $5.1(5.4)$ & $-5.0(-4.8)$ & $-44(-44)$ & $-50(-50)$ \\
$\mathrm{NO}_{3}$ & -0.42 & 0.38 & $3.8(3.9)$ & $-3.9(-3.9)$ & $-34(-31)$ & $-39(-31)$ \\
$\mathrm{O}_{3}$ & 0.21 & -0.17 & $1.0(0.63)$ & $-1.0(-1.3)$ & $-16(-15)$ & $-20(-19)$ \\
\hline $\mathrm{CO}$ & 1.2 & -1.6 & $-1.1(0.60)$ & $0.84(2.3)$ & $-28(-26)$ & $-47(-43)$ \\
Formaldehyde & 1.0 & -1.2 & $0.86(0.68)$ & $-1.1(-1.2)$ & $-14(-13)$ & $-15(-13)$ \\
$\mathrm{PANs}^{c}$ & 1.0 & -2.5 & $1.5(2.0)$ & $-3.0(-1.9)$ & $-54(-53)$ & $-62(-61)$ \\
$\mathrm{C}_{2+}$ nitrates $^{c}$ & 0.81 & -2.4 & $1.4(1.8)$ & $-3.1(-2.0)$ & $-67(-59)$ & $-75(-64)$ \\
Epoxides & 11 & -11 & -0.86 & 1.6 & -22 & -33 \\
Tetrafunctionals $^{c}$ & 4.4 & -12 & -5.0 & -2.7 & 29 & 53 \\
Isoprene SOA $^{c}$ & 15 & -8 & 2.9 & 3.9 & 48 & 74 \\
\hline $\mathrm{CH}_{4}$ lifetime & 0.82 & -0.59 & $-1.5(-1.1)$ & $1.9(1.9)$ & $9.8(7.8)$ & $6.3(4.22)$ \\
\hline
\end{tabular}

${ }^{a}$ Percent differences are annual averages from $4^{\circ} \times 5^{\circ}$ horizontal resolution GEOS-Chem simulations using RCIM;

${ }^{b}$ for simulations with changed $\mathrm{NO}_{\mathrm{x}}$ emissions, numbers in parentheses are the percent change that results from the same change in $\mathrm{NO}_{\mathrm{x}}$ emissions between two simulations with no isoprene emissions; ${ }^{c}$ percent differences in lumped classes of compounds are calculated by mole, not mass.

\section{S4 Isoprene oxidation at night}

Figures S6-S10 show the results of diurnal-steady-state and fixed-radical simulations of nighttime isoprene chemistry, which was also updated substantially in Wennberg et al. (2018) following the recommendations of Schwantes et al. (2015). For diurnal-steady-state simulations, figures S6 and S7 show average mixing ratios of isoprene oxidation products over the period 20:00-04:00 on the seventh simulated night; in general, due to the persistence of isoprene $+\mathrm{OH}$ oxidation products, these exhibit on minimal differences from daytime averages. Notably, the diurnal-steady-state simulations do not include nighttime changes to the mixed layer height or depositional and aerosol-phase losses, which may cause substantial biases.

In fixed-radical simulations, a series of simulations investigating $\mathrm{NO}_{3}$-initiated isoprene oxidation were performed alongside those investigating $\mathrm{OH}$-initiated oxidation. They were run similarly to those described in Section 2.2 of the main text, but instead of initializing with $1 \mathrm{ppbv}$ isoprene, they were initialized with 1 total ppbv of isoprene $+\mathrm{NO}_{3}+\mathrm{O}_{2}$ peroxy radicals, distributed across the peroxy radical isomers as in Wennberg et al. (2018). RCIM does not include many reactions of $\mathrm{NO}_{3}$ with stable isoprene oxidation products, because the rates and products of these reactions are poorly constrained. Instead, the mechanism emphasizes reactions of first-generation isoprene $+\mathrm{NO}_{3}$ products with $\mathrm{OH}$, which are expected to occur in the morning. The fixed-radical simulations were there run with $0.1 \mathrm{pptv} \mathrm{OH}$ and $10 \%$ of Equatorial midday light flux to target these morning conditions.

Figure $\mathrm{S} 8$ shows the yields of major products of isoprene $+\mathrm{NO}_{3}$ oxidation as simulated in fixed-radical box models with RCIM, including functionalized nitrates and the epoxides produced in their reactions with OH (Jacobs et al., 2014; Schwantes et al., 2015). Figure S9 compares these yields to those of fixed-radical simulations using the MCM v3.3.1 isoprene oxidation mechanism, which exhibits much higher formation of carbonyl nitrates and much lower production of $\mathrm{C}_{4}$ nitrates, ethanal nitrate, and epoxides. Figure S10 compares RCIM to the GEOS-Chem v11-02c mechanism in fixed-radical nighttime simulations. The GEOSChem mechanism includes a smaller pool of functional products from isoprene $+\mathrm{NO}_{3}$ oxidation, with high yields of $\mathrm{C}_{5}$ hydroxy- and hydroperoxy-nitrates and only minor yields of the other products shown in RCIM. 


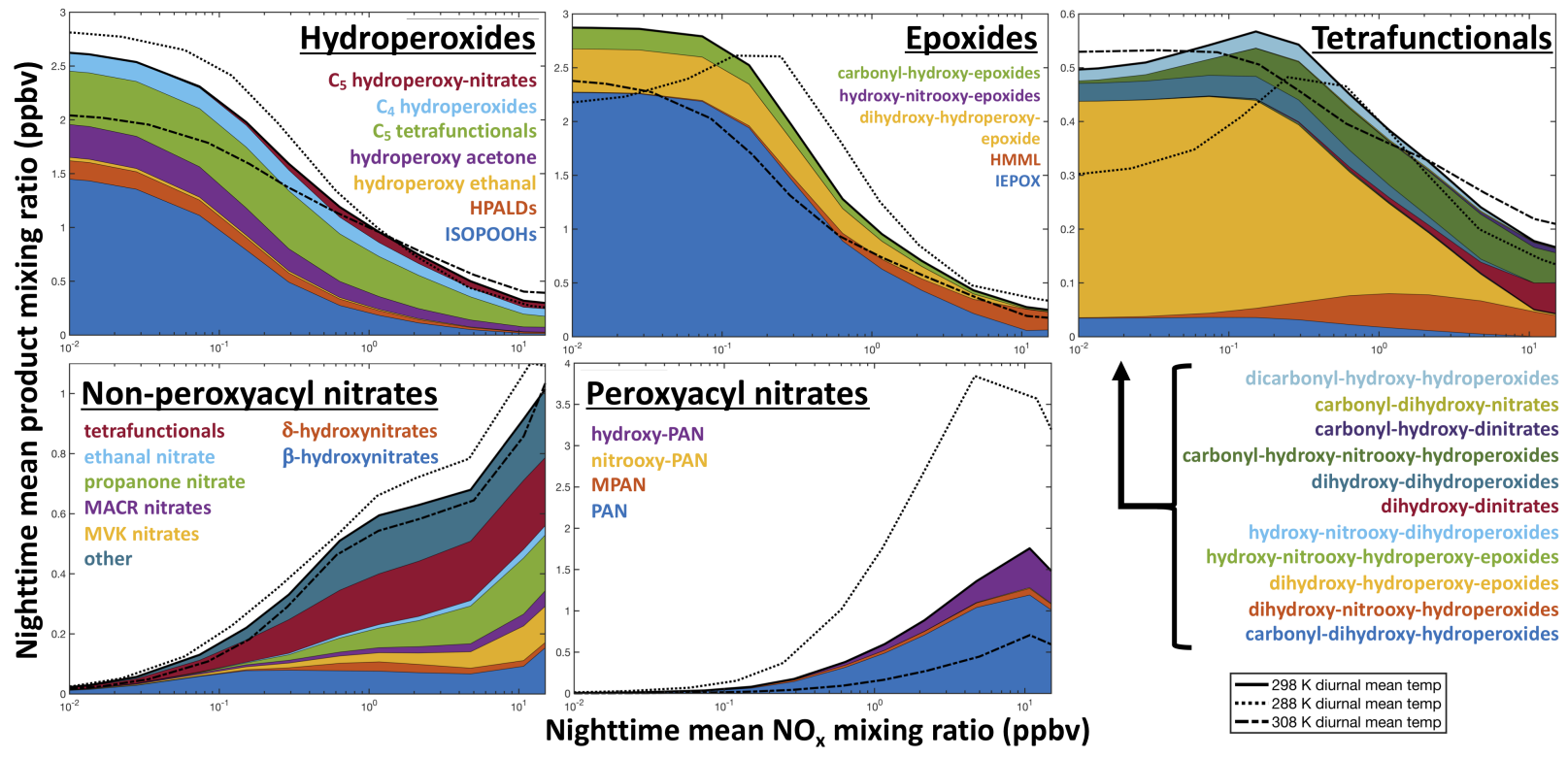

Figure S6: Nighttime average mixing ratios of major classes of compounds from isoprene oxidation in diurnalsteady-state box models as functions of $\mathrm{NO}_{x}$ and temperature, using RCIM. Y axis scales vary between graphs. 


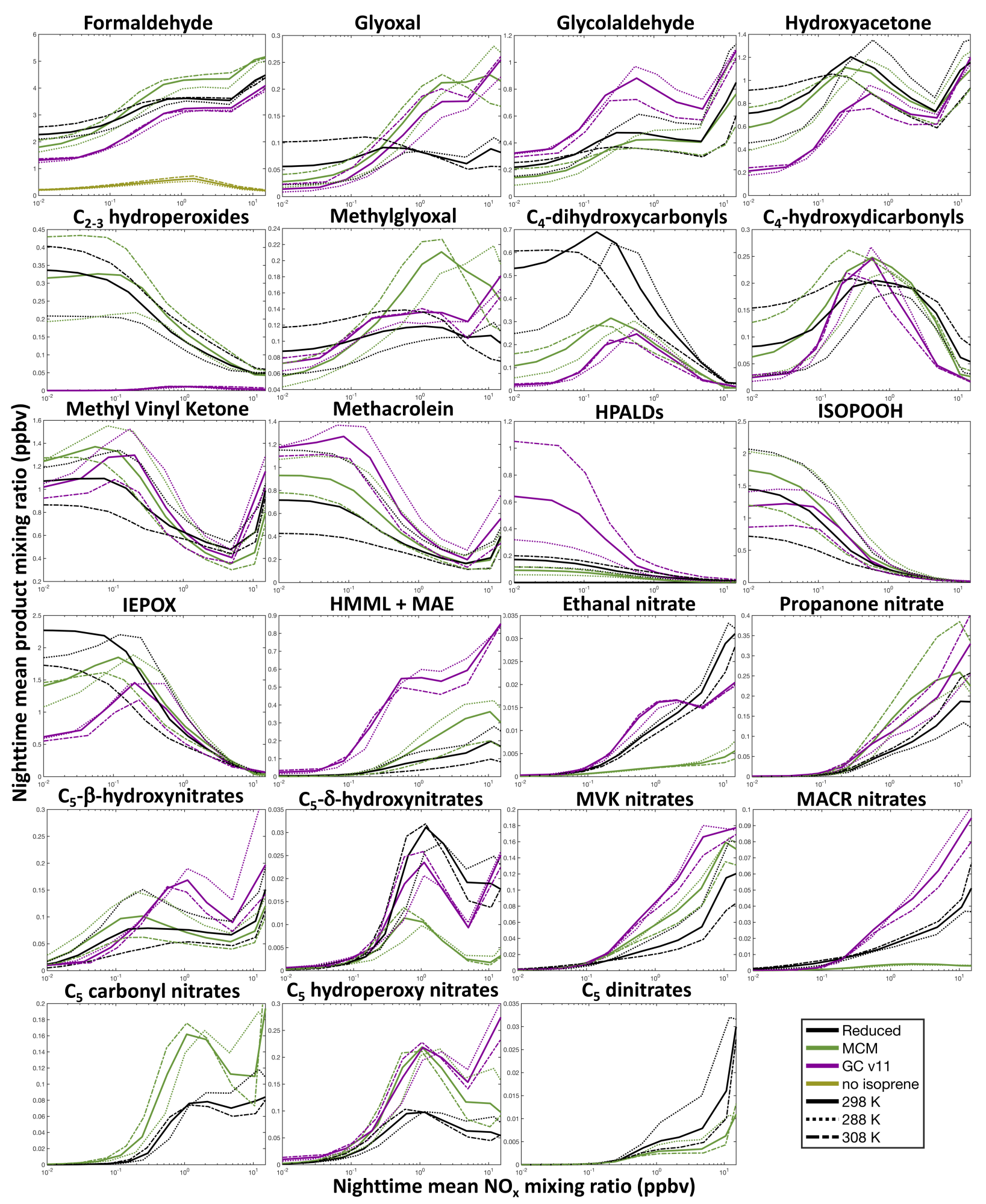

Figure S7: Nighttime average mixing ratios of major products of isoprene oxidation in diurnal-steady-state box models as functions of $\mathrm{NO}_{x}$ and temperature, using RCIM. Y axis scales vary between graphs. For formaldehyde, the model assumes a background mixing ratio of $300 \mathrm{pptv}$, with some additional contribution from methane oxidation. For HPETHNL + HPAC, $¡ 10 \%$ of the total is contributed by HPETHNL under all conditions. 


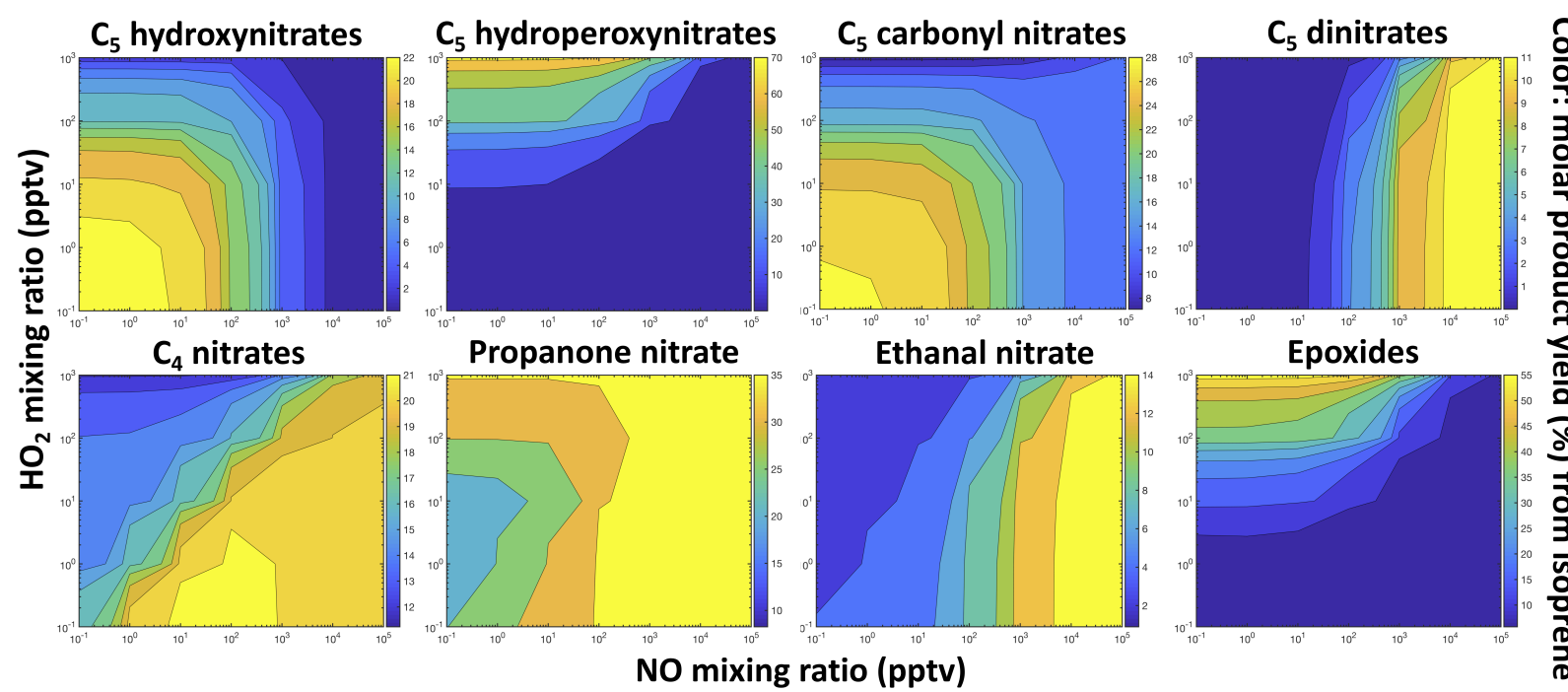

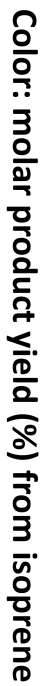

Figure S8: Percent yields of compounds of interest from isoprene $+\mathrm{NO}_{3}$ oxidation in RCIM. All box models are run at $25{ }^{\circ} \mathrm{C}$ and $10 \%$ of equatorial midday photolytic light flux.
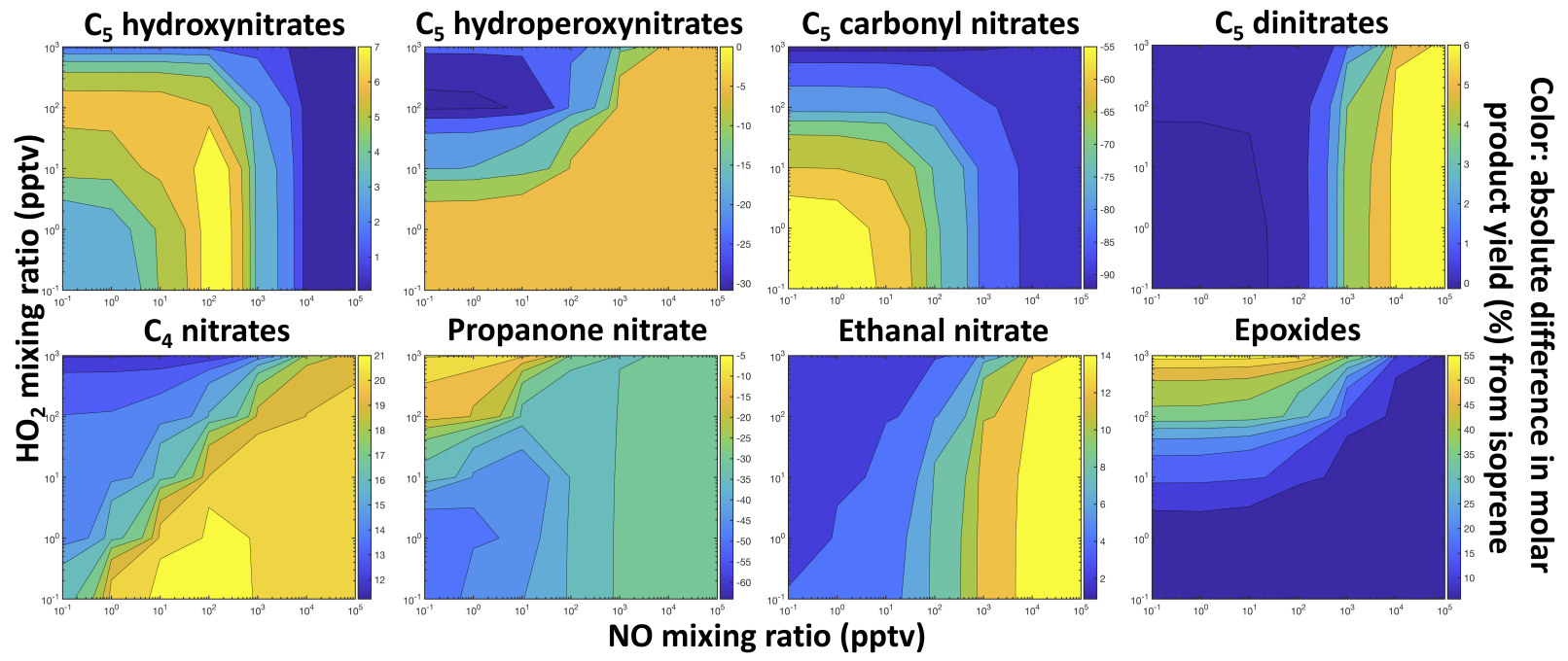

Figure S9: Absolute changes in percent yields of compounds of interest from isoprene $+\mathrm{NO}_{3}$ oxidation when switching from fixed-radical box models with the MCM v3.3.1 mechanism (Jenkin et al., 2015) to RCIM. All box models are run at $25{ }^{\circ} \mathrm{C}$ and $10 \%$ of equatorial midday photolytic light flux.

\section{S5 Comparisons to other mechanisms}

Figures S11-S24 show detailed comparisons between RCIM, MCM v3.3.1, and the GEOS-Chem v11-02c isoprene oxidation mechanisms in box models, and between RCIM and v11-02c in global simulations. Many differences between the mechanisms stem from variability in the initial reactive pathway branching of isoprene, shown in Section S5.1, and from differences between the OH-recycling tendencies of the mechanisms under low-NO conditions (Section S5.2). These differences then carry over into variability in the yields of organic products (Section S5.3). 


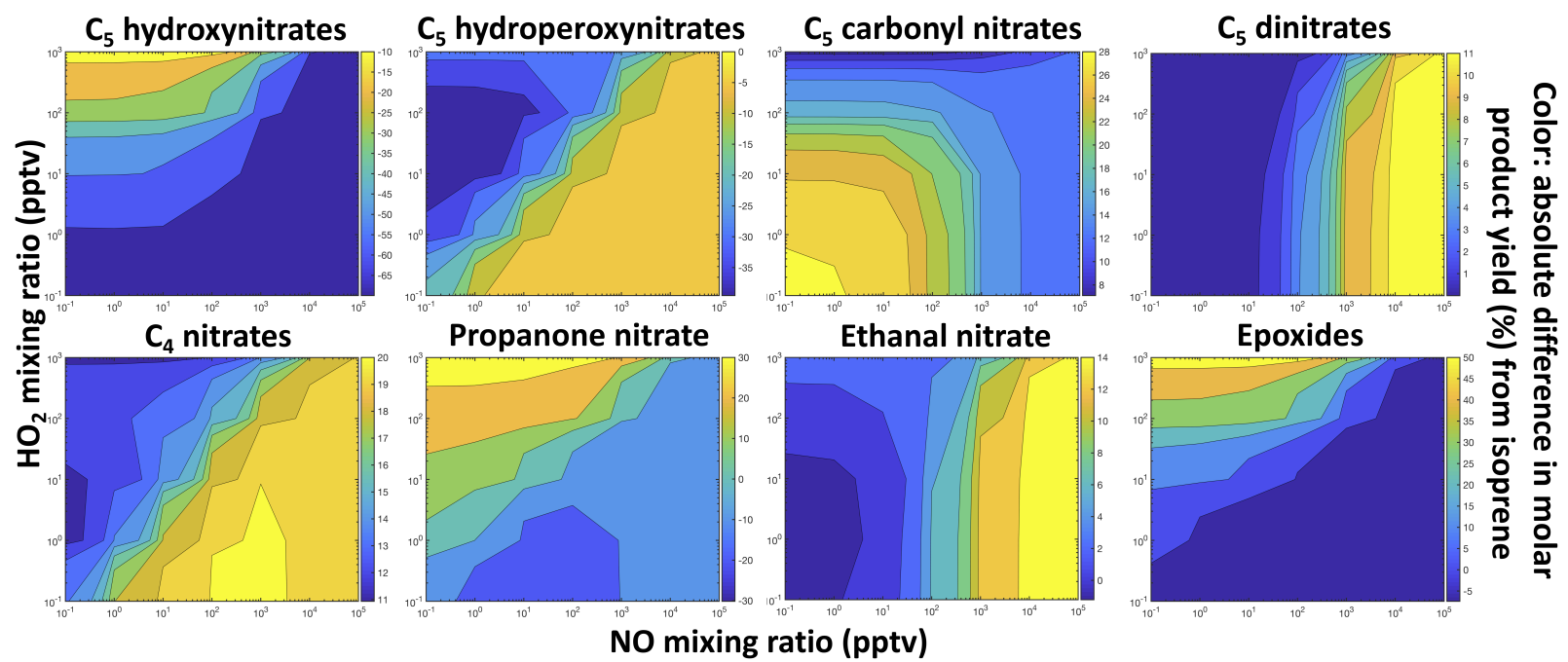

Figure S10: Absolute changes in percent yields of compounds of interest from isoprene $+\mathrm{NO}_{3}$ oxidation when switching from fixed-radical box models with the GEOS-Chem v11-02c mechanism to RCIM. All box models are run at $25{ }^{\circ} \mathrm{C}$ and $10 \%$ of equatorial midday photolytic light flux.

\section{S5.1 Isoprene reaction pathways}

Figure S11 shows the contributions of specific reactive pathways to the overall fate of isoprene in diurnalsteady-state box models with the three isoprene oxidation mechanisms. Lower $\mathrm{OH}$ recycling under low-NO conditions in the MCM and GEOS-Chem mechanisms relative to RCIM means that less $\mathrm{OH}$ is available to react with isoprene, and leads to a higher reactivity with ozone, by up to a factor of 2 in the MCM mechanism and over a factor of 3 in the GEOS-Chem v11-02c mechanism. This effect is also visible in global chemical transport simulations with RCIM and v11-02c (Figure S12). The increased $\mathrm{OH}$ recycling in RCIM also sustains higher $\mathrm{HO}_{2}$ mixing ratios, which leads to a larger fraction of ISOPOO reacting with $\mathrm{HO}_{2}$ than in the other mechanisms. Fixed-radical simulations (Figure S13 and S14) show that when NO and $\mathrm{HO}_{2}$ are held constant, RCIM results in a larger proportion of ISOPOO reacting via $\mathrm{H}$-shifts than the other two mechanisms, and only deviates substantially from MCM in the fraction reacting via each isomer under extremely high-NO conditions.

\section{S5.2 $\mathrm{HO}_{\mathrm{x}}, \mathrm{NO}_{\mathrm{x}}$, and ozone}

Figures S15 and S16 show the differences in net production of $\mathrm{HO}_{x}, \mathrm{NO}_{x}$ and ozone due to isoprene oxidation by the three different mechanisms in fixed-radical box models. As described in the main manuscript, the main difference between the mechanisms is the higher $\mathrm{HO}_{x}$ recycling in RCIM under conditions where $\mathrm{H}$ shift chemistry dominates. This can also be seen in global simulations comparing GEOS-Chem v11-02c and RCIM (Figure S17), which show that RCIM sustains OH concentrations up to three times those of the GEOS-Chem v11-02c mechanism in remote regions of high isoprene emission such as the Amazon, and that the reduced MPAN formation rate in RCIM leads to much lower $\mathrm{NO}_{x}$ titration over the Amazon. 
Fate of isoprene

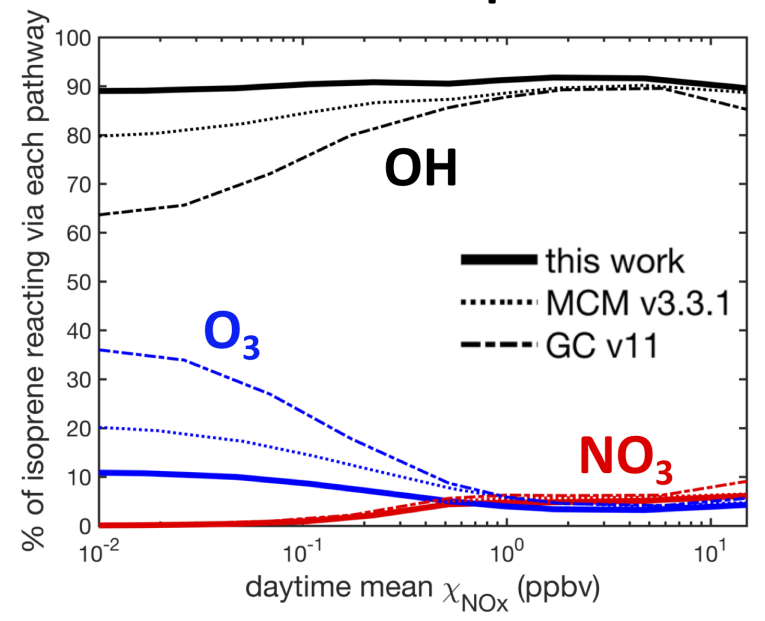

Fate of ISOPOO

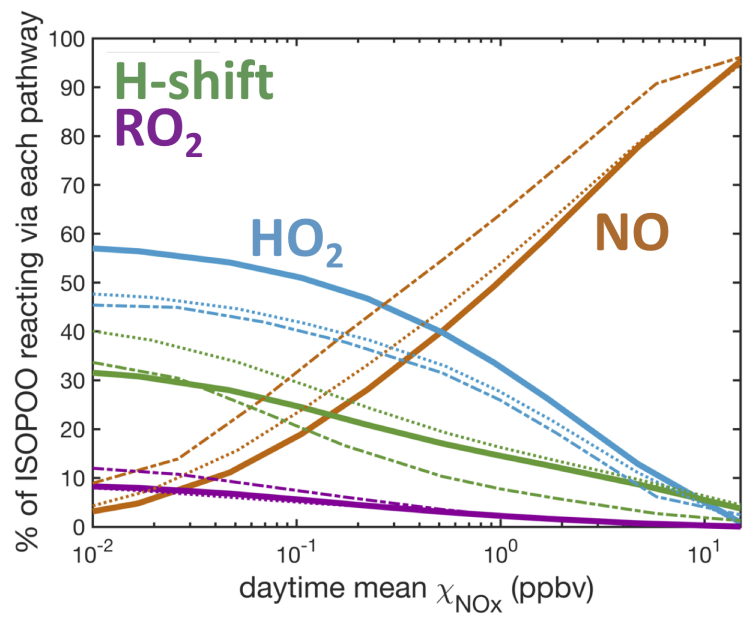

Figure S11: Isoprene oxidation pathway branchings in diurnal-steady-state box models as a function of $\mathrm{NO}_{\mathrm{x}}$ mixing ratio, using RCIM (solid), MCM v3.3.1 (dashed), and GEOS-Chem v11-02c (dotted).
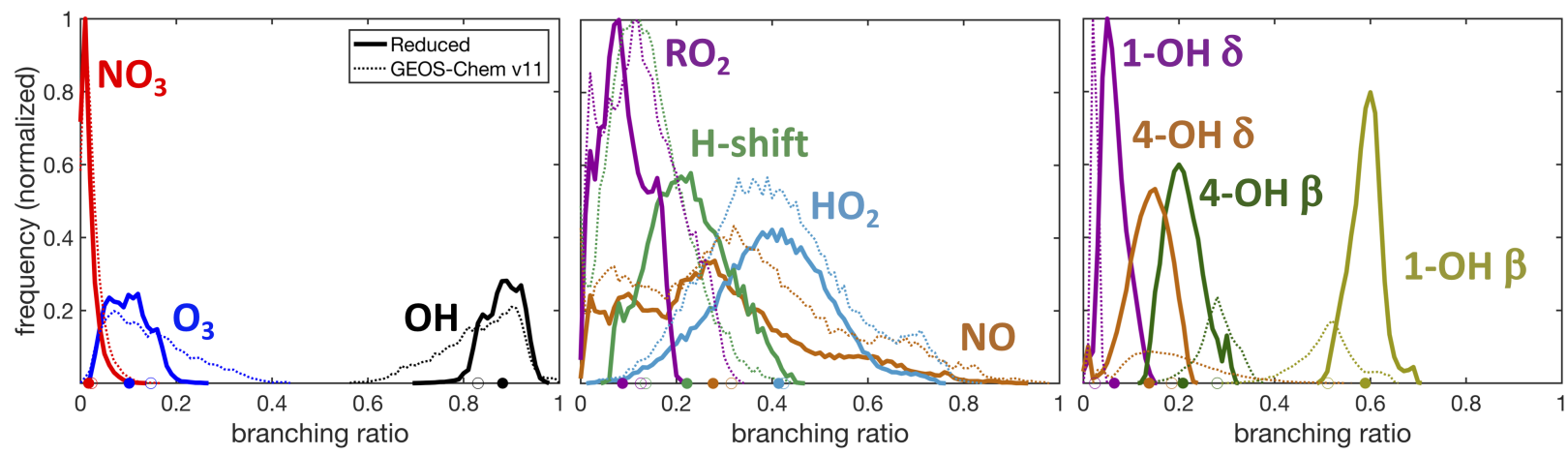

Figure S12: Isoprene oxidation pathway branchings in GEOS-Chem using RCIM (solid lines, filled dots) and GEOS-Chem v11-02c (dotted lines, open dots), at $2^{\circ} \times 2.5^{\circ}$ horizontal resolution, on an annual average. The curves represent probability density functions of the models grid boxes, weighted by the amount of isoprene reacting in each grid box, while the dots on the $\mathrm{x}$ axis represent the global annual total reacting via each pathway. 


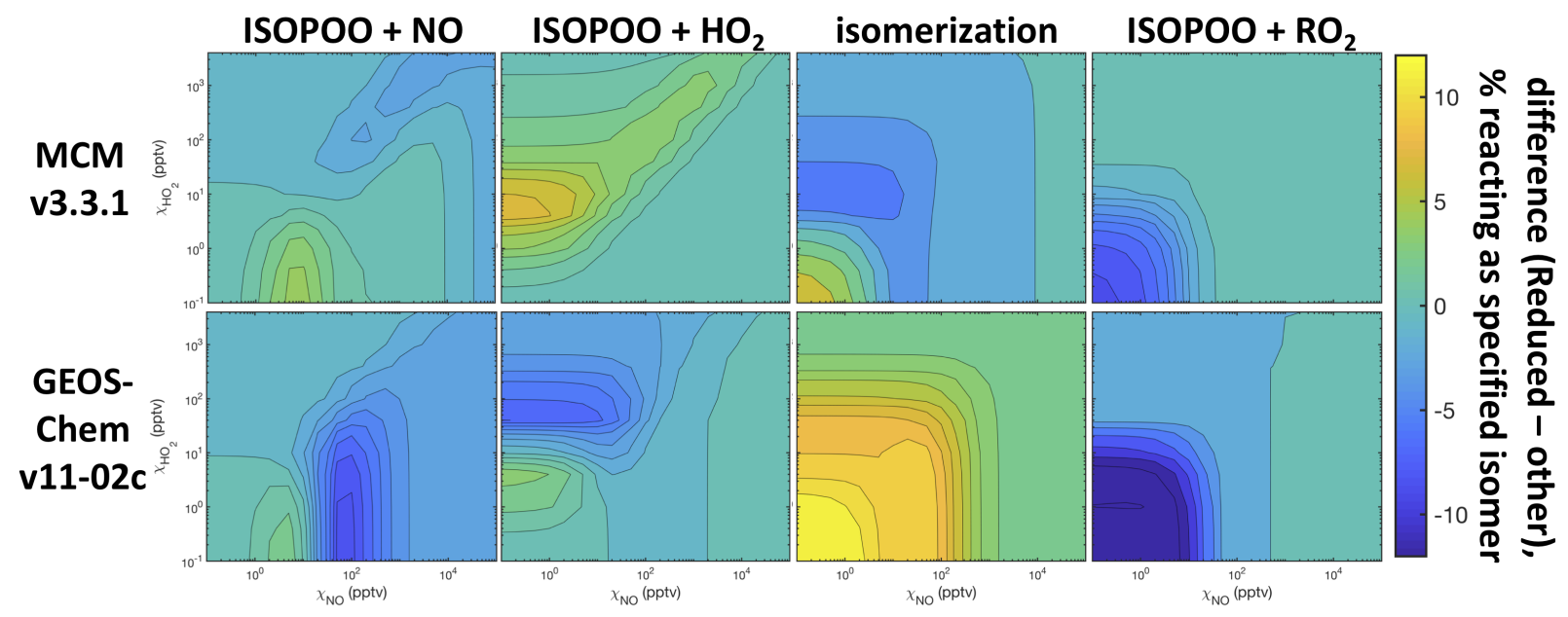

Figure S13: Absolute difference between RCIM and MCM v3.3.1 (top) and GEOS-Chem v11-02c (bottom) in the percent of isoprene hydroxy peroxy radicals reacting via each pathway as a function of $\mathrm{NO}$ and $\mathrm{HO}_{2}$, from fixed-radical box modeling of all three mechanisms at $298 \mathrm{~K}$ and full photolytic sunlight flux (equatorial midday).

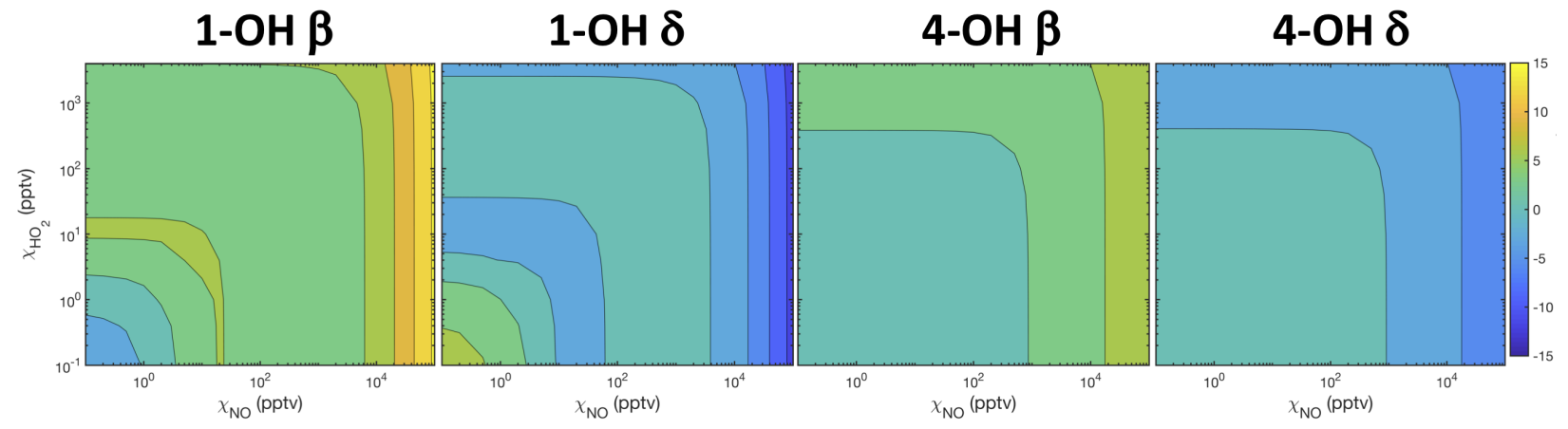

Figure S14: Absolute difference between RCIM and MCM v3.3.1 mechanism in the percent of isoprene hydroxy peroxy radicals reacting via each isomer as a function of $\mathrm{NO}$ and $\mathrm{HO}_{2}$, from fixed-radical box modeling of all three mechanisms at $298 \mathrm{~K}$ and full photolytic sunlight flux (equatorial midday). 


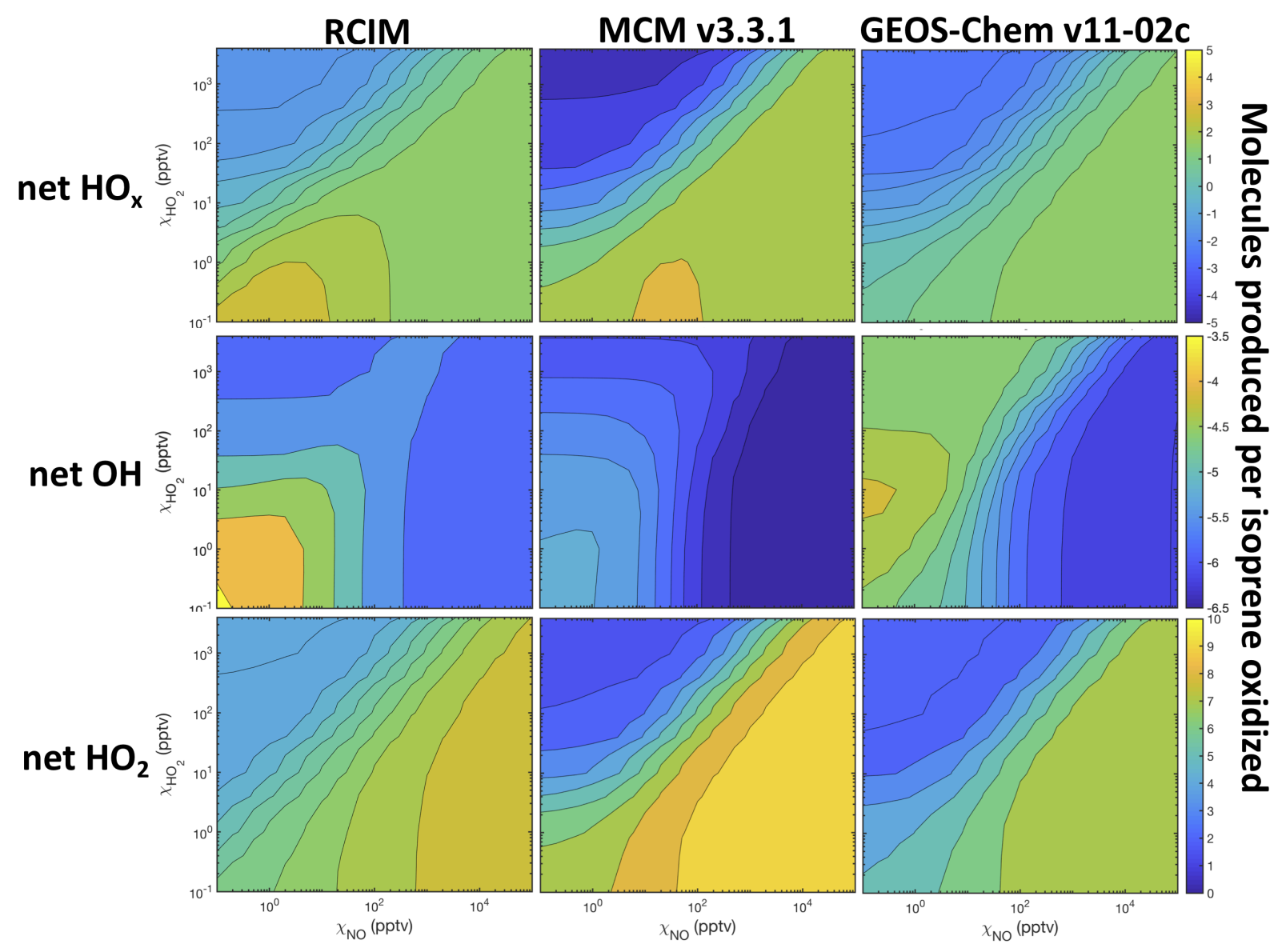

Figure S15: Net molar production or consumption of $\mathrm{HO}_{\mathrm{x}}, \mathrm{OH}$, and $\mathrm{HO}_{2}$ from isoprene oxidation as a function of $\mathrm{NO}$ and $\mathrm{HO}_{2}$ in RCIM (top), MCM v3.3.1 (middle) and GEOS-Chem v11-02c (bottom), from fixed-radical box modeling of all three mechanisms at $298 \mathrm{~K}$ and full photolytic sunlight flux (equatorial midday). 


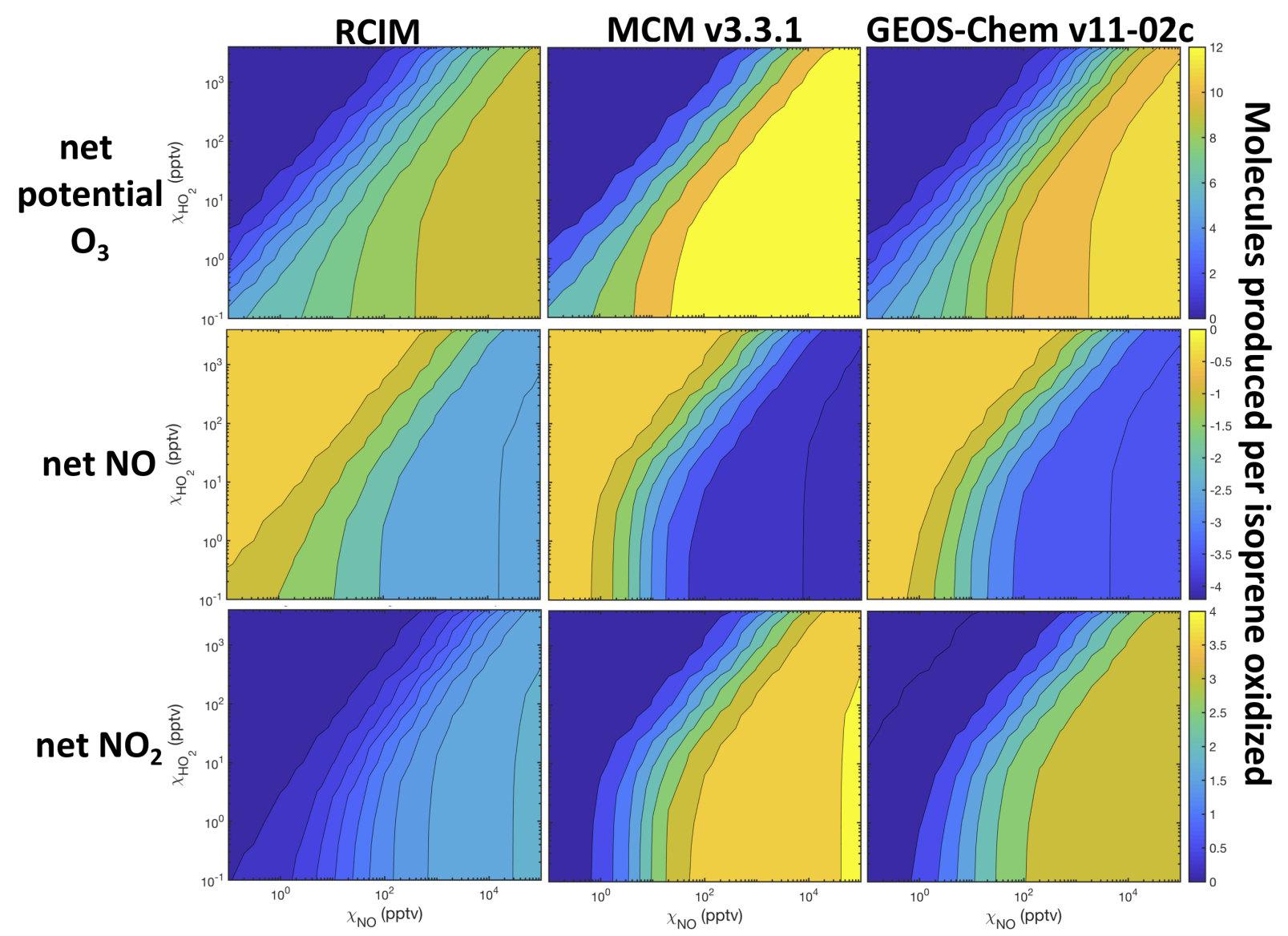

Figure S16: Net molar production or consumption of potential $\mathrm{O}_{3}, \mathrm{NO}$, and $\mathrm{NO}_{2}$ from isoprene oxidation as a function of $\mathrm{NO}$ and $\mathrm{HO}_{2}$ in RCIM (top), MCM v3.3.1 (middle) and GEOS-Chem v11-02c (bottom), from fixed-radical box modeling of all three mechanisms at $298 \mathrm{~K}$ and full photolytic sunlight flux (equatorial midday). Net potential $\mathrm{O}_{3}$ is estimated as the sum of net production of ozone, $\mathrm{NO}_{2}$, and $\mathrm{HO}_{2}$ (times the fraction of $\mathrm{HO}_{2}$ that would go on to react with $\mathrm{NO}$ based on the relative concentrations of its potential reaction partners). 

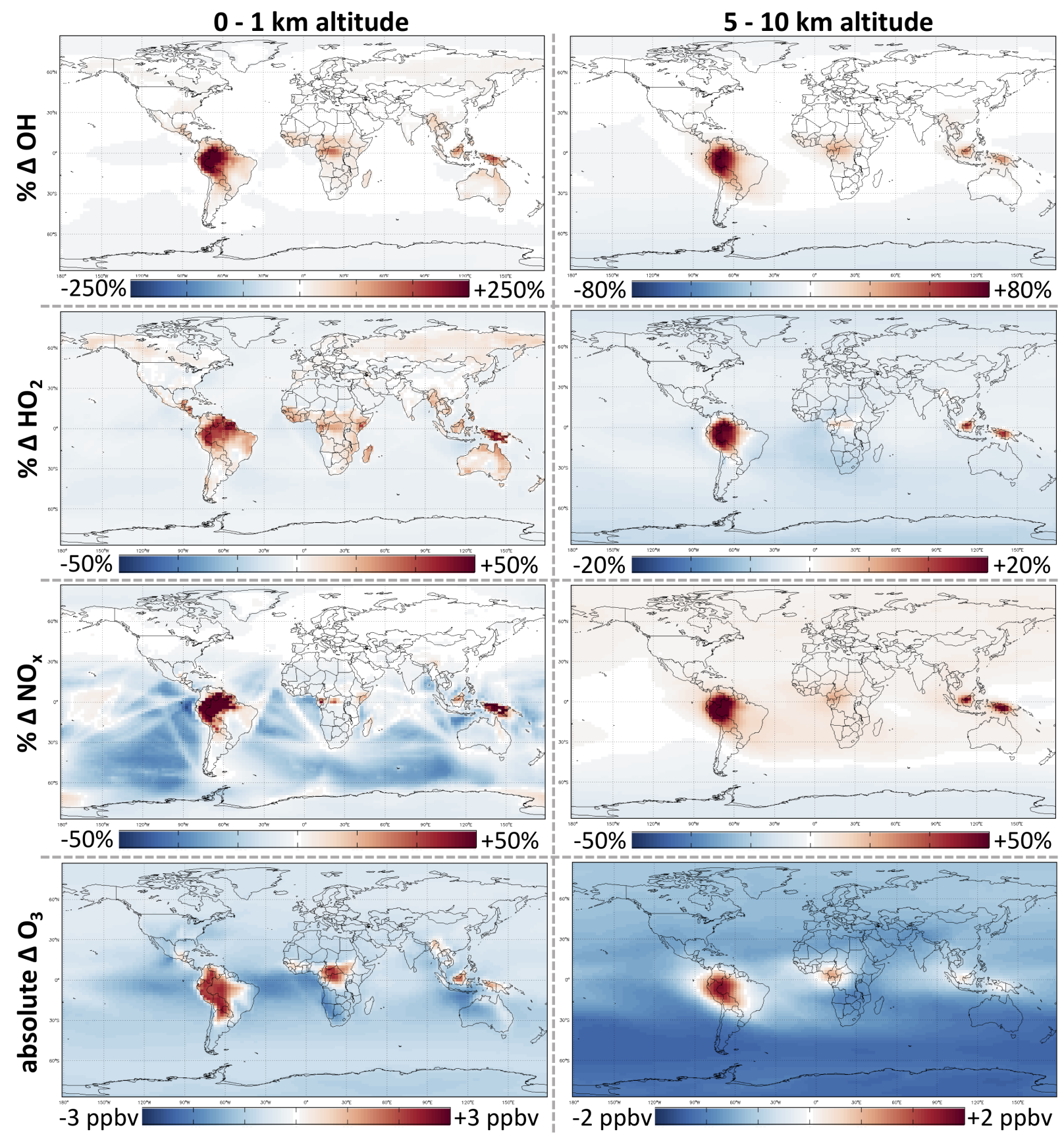

Figure S17: Changes in annual average mixing ratios of $\mathrm{OH}, \mathrm{HO}_{2}, \mathrm{NO}_{x}$, and $\mathrm{O}_{3}$ from a $2^{\circ} \times 2.5^{\circ}$ horizontal resolution GEOS-Chem simulation with the GEOS-Chem v11-02c mechanism to one with RCIM.

\section{S5.3 Organic products}

Figures S18 and S19 show the differences in yields of organic products between RCIM, MCM v3.3.1, and GEOS-Chem v11-02c in fixed-radical box model simulations. Figures S20-S23 show differences in daytime mixing ratios of organic products between the mechanisms in diurnal-steady-state simulations. Figure S24 shows differences in mean annual mixing ratios of organic isoprene oxidation products between GEOS-Chem v11-02c and RCIM in global chemical transport simulations. These maps show the higher formaldehyde 
production from local isoprene oxidation over remote forests as well as the strong effects of the decreased MPAN formation rate in RCIM, along with smaller corresponding decreases in PAN formation and in the lifetimes of tertiary nitrates due to rapid hydrolysis. The major differences between product yields are noted in the main manuscript; these figures are provided as a reference for those seeking a more detailed accounting of individual products.

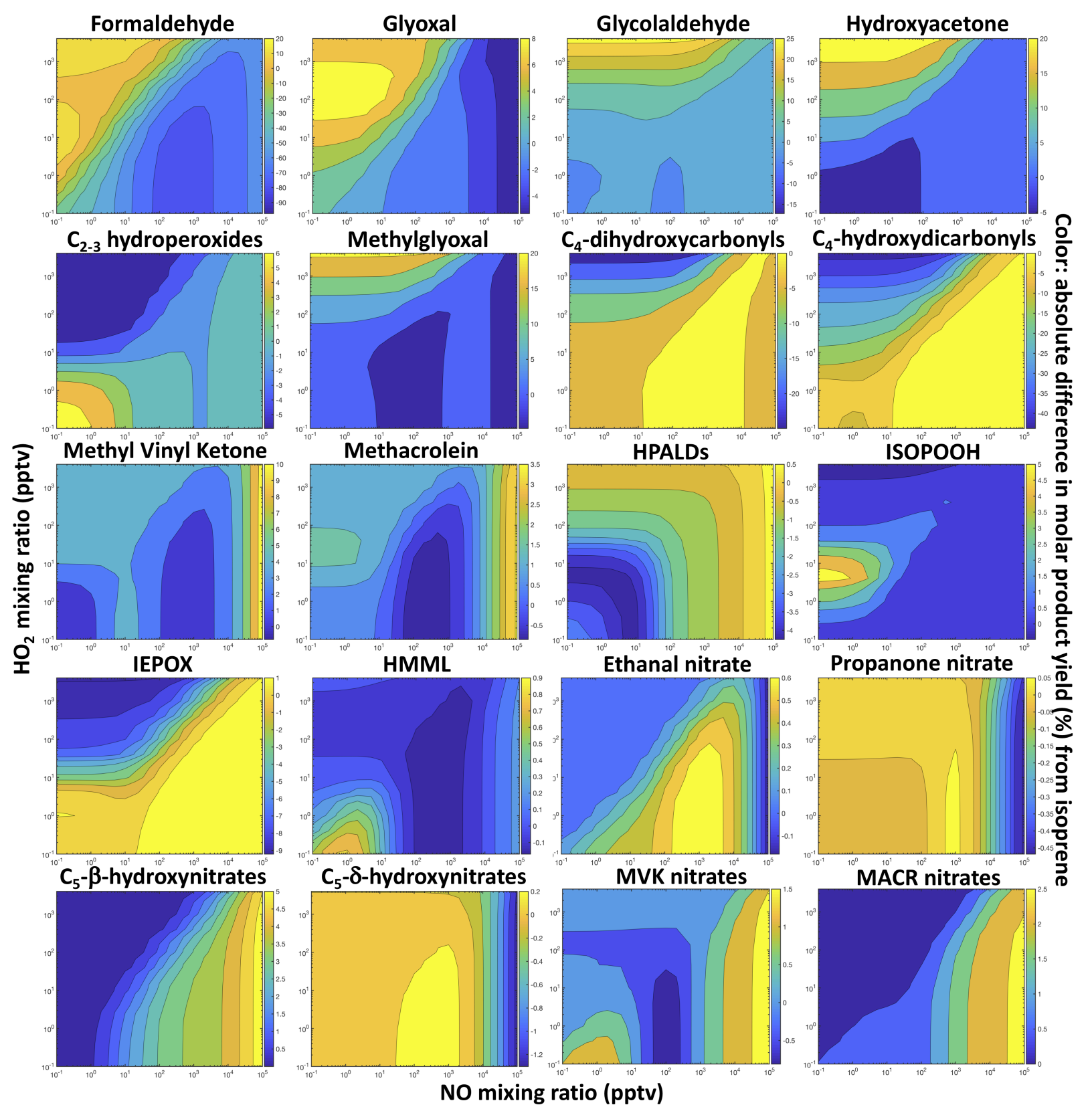

Figure S18: Absolute changes in percent yields of compounds of interest from isoprene $+\mathrm{OH}$ oxidation when switching from fixed-radical box models with MCM v3.3.1 (Jenkin et al., 2015) to RCIM. All box models are run at $25^{\circ} \mathrm{C}$ and equatorial midday photolytic light flux. 


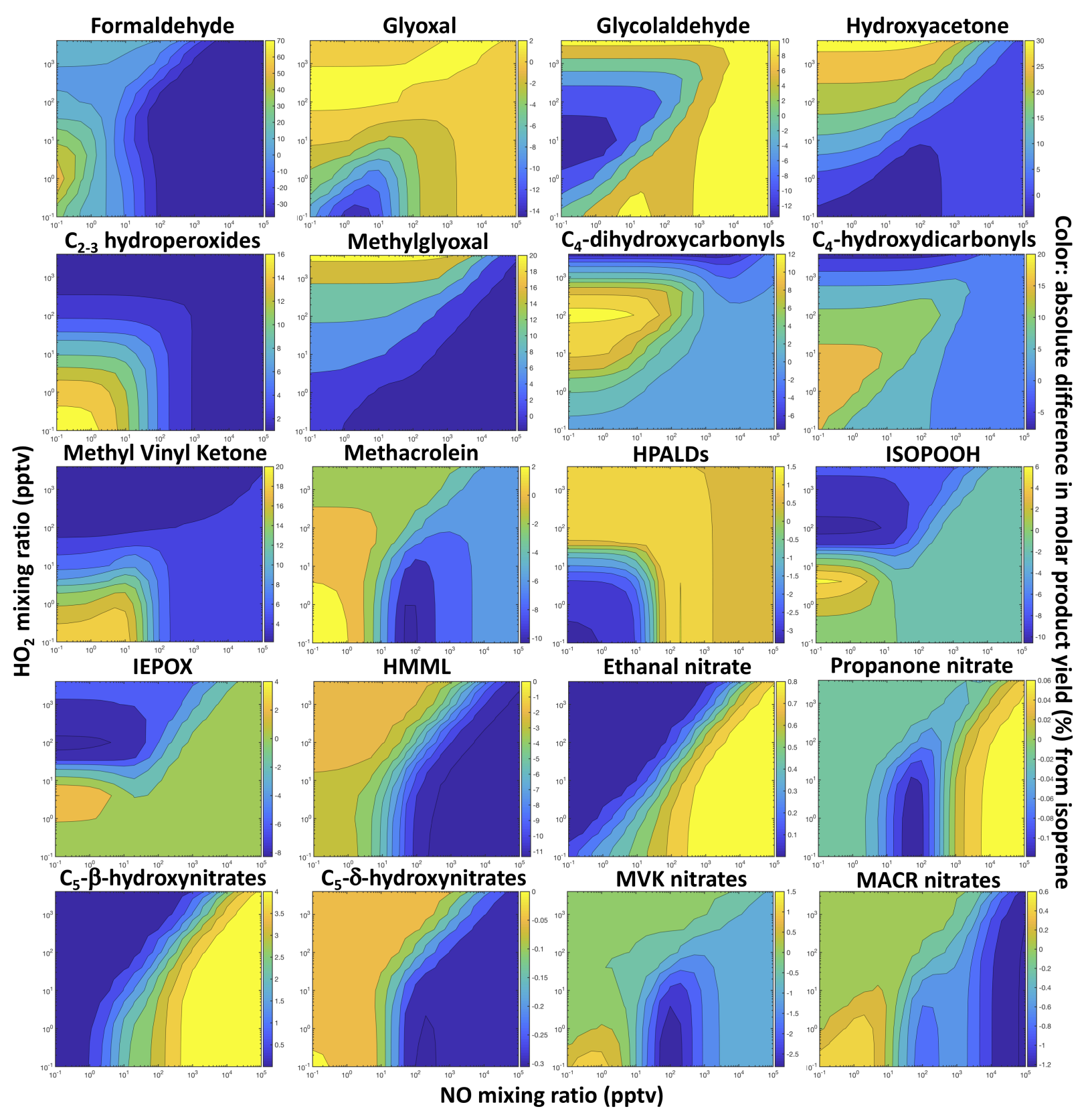

Figure S19: Absolute changes in percent yields of compounds of interest from isoprene $+\mathrm{OH}$ oxidation when switching from fixed-radical box models with GEOS-Chem v11-02c (Jenkin et al., 2015) to RCIM. All box models are run at $25{ }^{\circ} \mathrm{C}$ and equatorial midday photolytic light flux. 


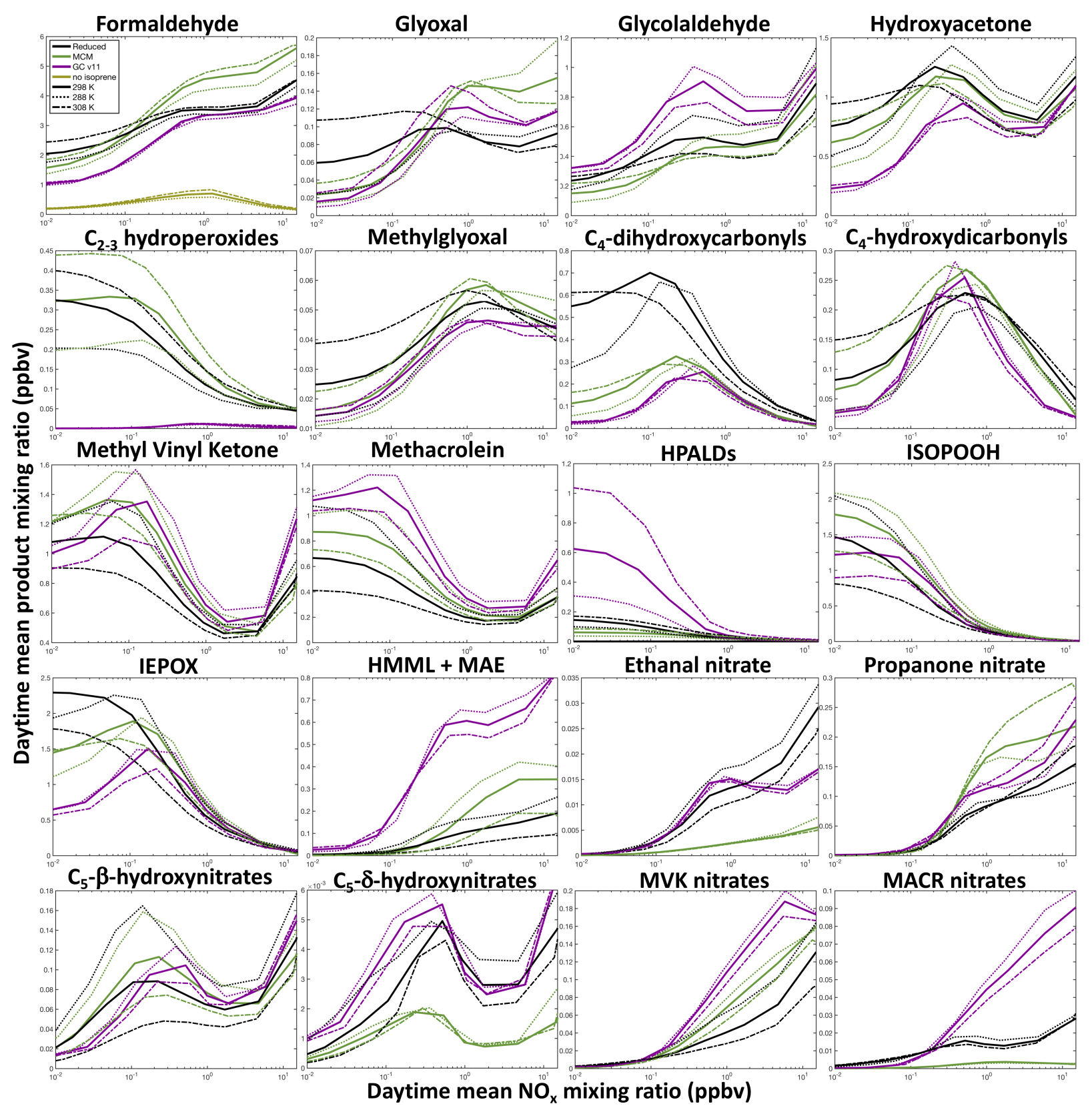

Figure S20: Daytime average mixing ratios of isoprene oxidation products in diurnal-steady-state box models as a function of $\mathrm{NO}_{\mathrm{x}}$ mixing ratio (X axis) and temperature (line style), using RCIM (black), MCM v3.3.1 (green), and GEOS-Chem v11-02c (purple). 


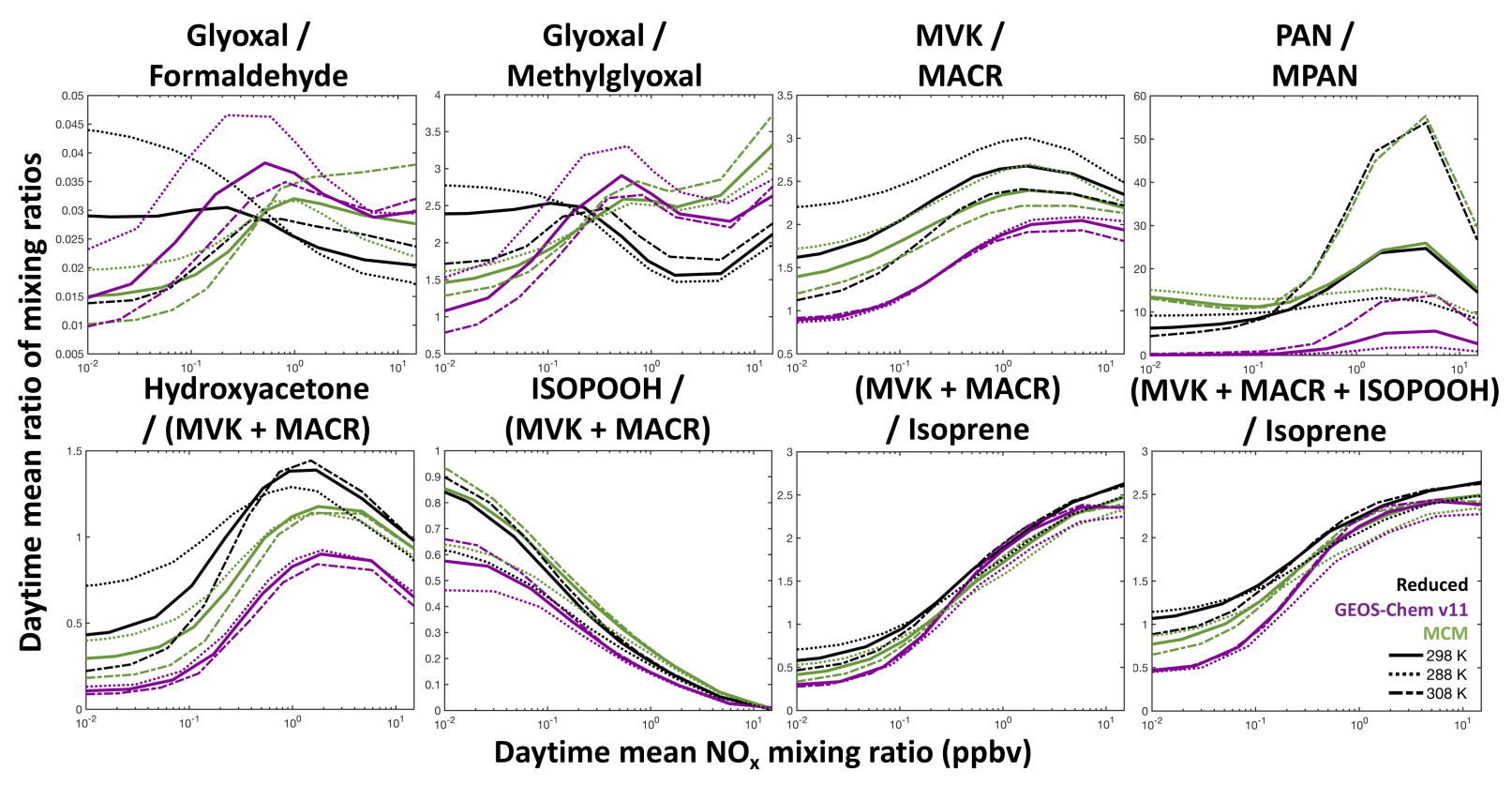

Figure S21: Commonly reported ratios between daytime average mixing ratios of isoprene oxidation products in diurnal-steady-state box models as a function of $\mathrm{NO}_{\mathrm{x}}$ mixing ratio (X axis) and temperature (line style), using RCIM (black), MCM v3.3.1 (green), and GEOS-Chem v11-02c (purple).
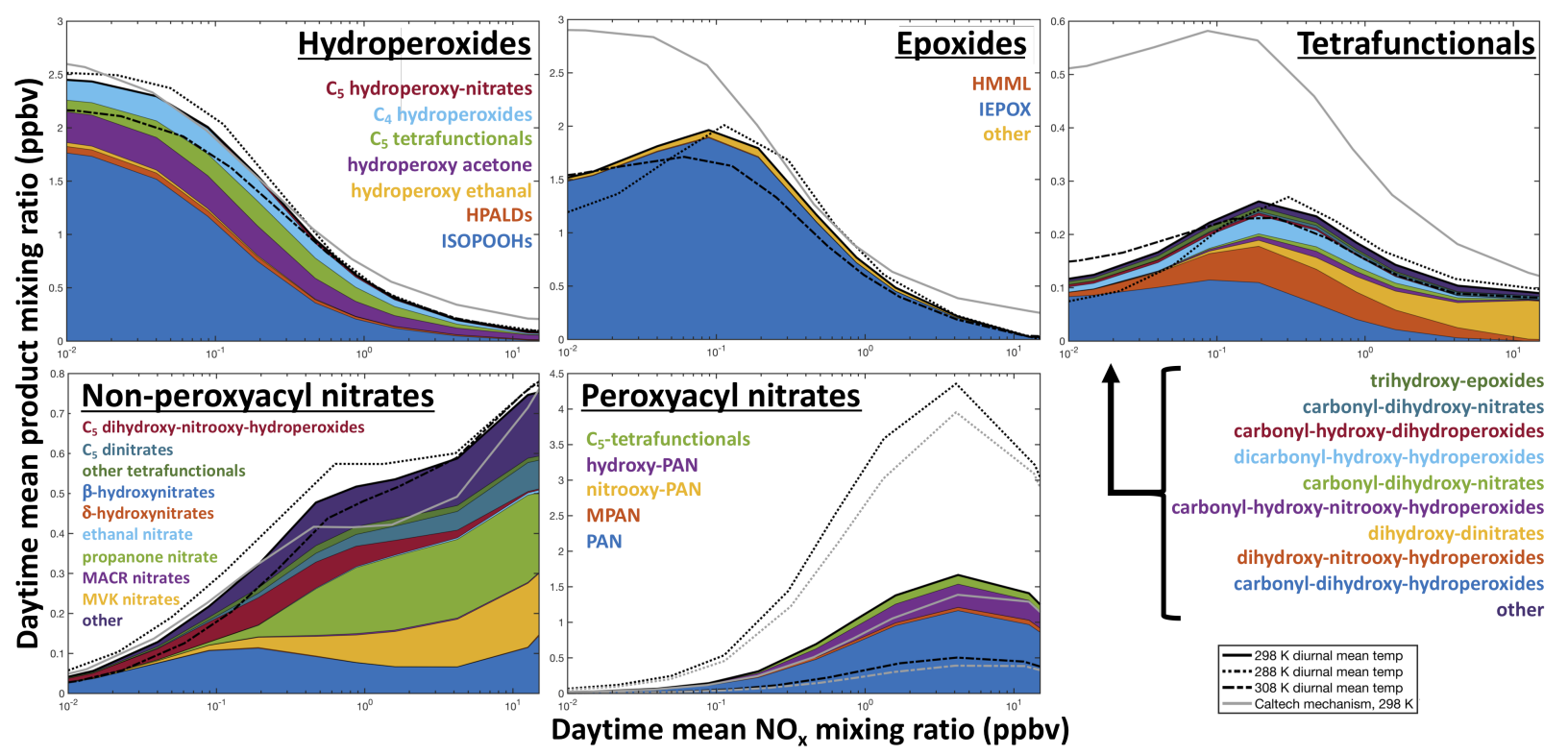

Figure S22: Daytime average mixing ratios of major classes of compounds from isoprene oxidation in diurnalsteady-state box models as functions of $\mathrm{NO}_{x}$ (X axis) and temperature (black lines), using MCM v3.3.1. $\mathrm{Y}$ axis scales vary between graphs. Grey lines denote corresponding mixing ratios using the RCIM for comparison. 


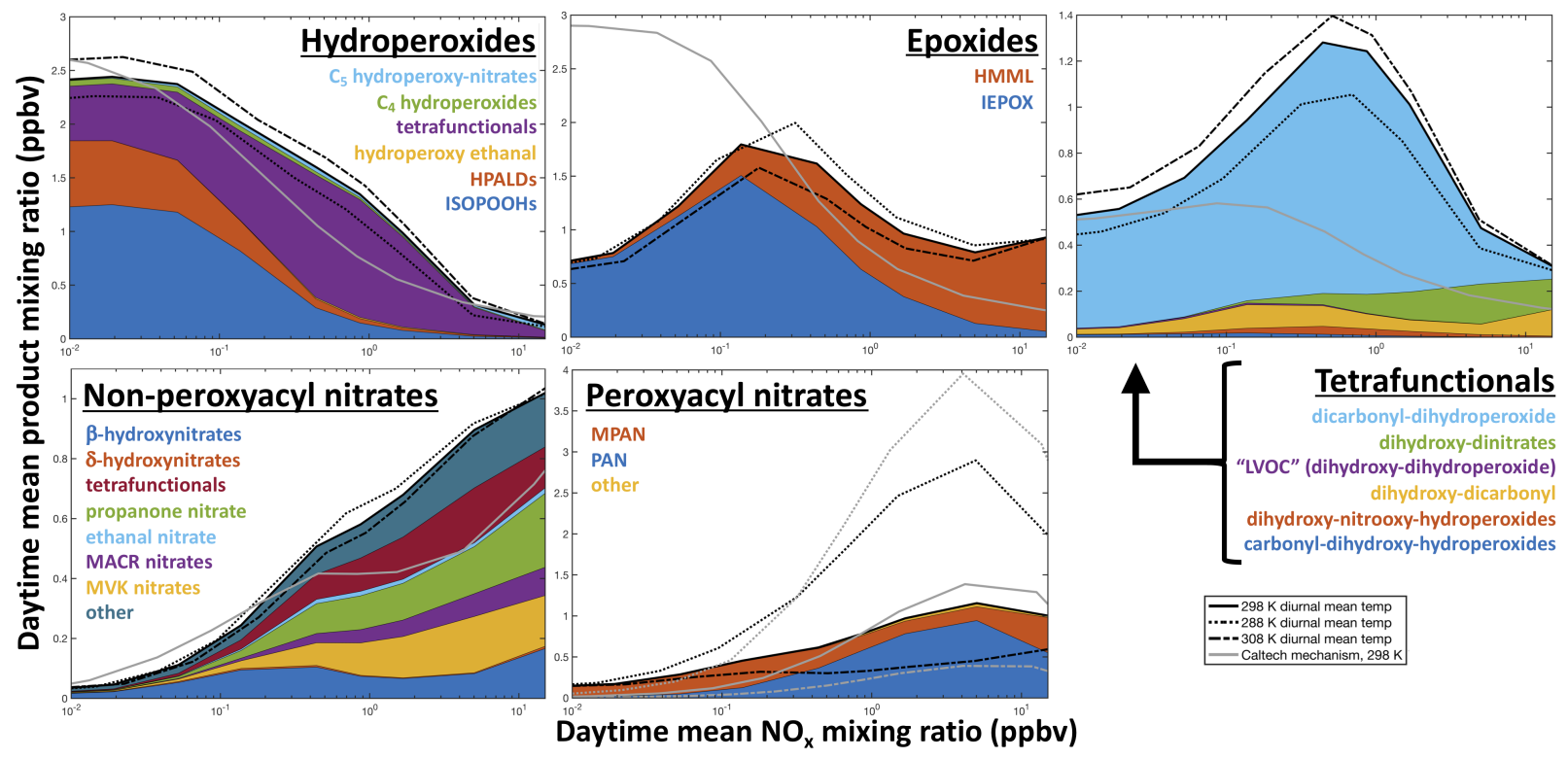

Figure S23: Daytime average mixing ratios of major classes of compounds from isoprene oxidation in diurnalsteady-state box models as functions of $\mathrm{NO}_{x}$ (X axis) and temperature (black lines), using GEOS-Chem v11-02c. Y axis scales vary between graphs. Grey lines denote corresponding mixing ratios using RCIM for comparison. 

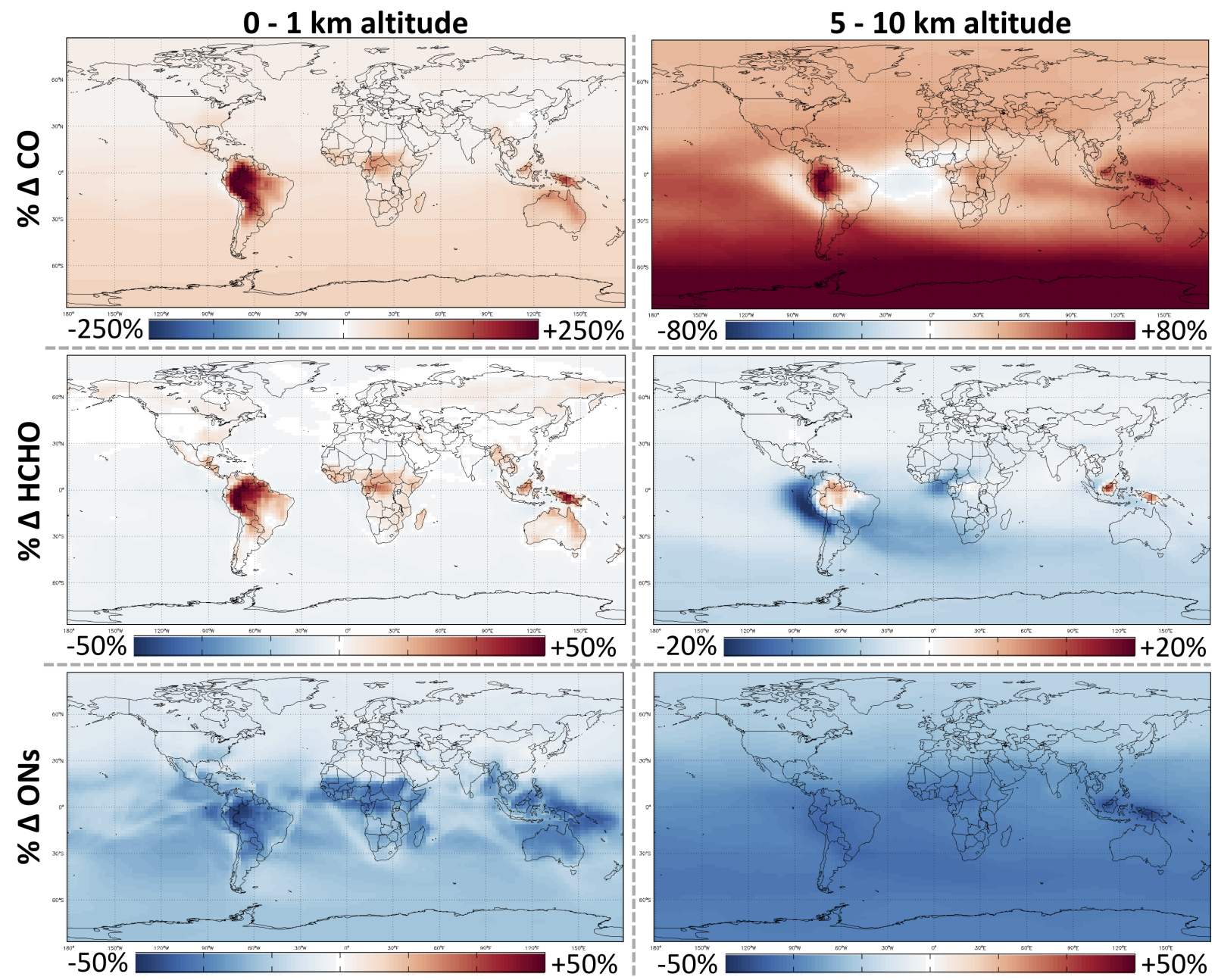

Figure S24: Percent changes in annual average mixing ratios of CO (top), formaldehyde (middle), and total organonitrates (bottom) from a $2^{\circ} \times 2.5^{\circ}$ horizontal resolution GEOS-Chem simulation with the GEOS-Chem v11-02c mechanism to one with RCIM. 


\section{S6 Mechanism simplification}

Table S6 provides the differences in tropospheric and regional production and mixing ratios of species between annual GEOS-Chem simulations using RCIM and Mini-CIM. As described in the main text, the changes between the two mechanisms are minimal $(\sim 0.1 \%)$, particularly for $\mathrm{HO}_{x}, \mathrm{NO}_{x}, \mathrm{O}_{3}, \mathrm{CO}$, and $\mathrm{HCHO}$. Larger reductions in $\mathrm{C}_{2+}$ organonitrate $(2.8 \%)$ and $\mathrm{C}_{5}$ tetrafunctional (12\%) production are largely due to the removal of multigenerational steps (e.g. the conversion of one tetrafunctional species into another), and therefore do not carry over substantially to changes in mixing ratios. Further, the moderate percent reduction $(4.4 \%)$ in mixing ratios of organonitrates over the Amazon represents only a tiny absolute difference, since the region experiences very little nitrate formation.

Table S6: Differences (\%) in annual production and mixing ratios between GEOS-Chem simulations using RCIM and Mini-CIM

\begin{tabular}{ccccccc}
\hline & $\begin{array}{c}\text { tropospheric } \\
\text { production }\end{array}$ & $\begin{array}{c}\text { tropospheric } \\
\text { loading }\end{array}$ & $\begin{array}{c}\text { loading, } \\
0-1 \mathrm{~km}\end{array}$ & $\begin{array}{c}\text { loading, } \\
\text { Amazon }\end{array}$ & $\begin{array}{c}\text { loading, } \\
\text { SE USA }\end{array}$ & $\begin{array}{c}\text { loading, } \\
\text { E China }\end{array}$ \\
\hline $\mathrm{OH}$ & - & -0.14 & -0.12 & -0.17 & -0.03 & -0.01 \\
$\mathrm{HO}_{2}$ & - & $-3.2 \mathrm{E}-3$ & -0.022 & -0.020 & 0.079 & 0.025 \\
$\mathrm{NO}_{\mathrm{x}}$ & - & -0.17 & -0.02 & -0.22 & 0.020 & 0.016 \\
$\mathrm{O}_{3}$ & - & -0.11 & -0.097 & -0.42 & -0.074 & -0.028 \\
$\mathrm{CO}$ & -0.11 & -0.078 & 0.054 & 0.038 & 0.014 & $5.1 \mathrm{E}-3$ \\
$\mathrm{HCHO}$ & -0.13 & -0.096 & -0.11 & -0.12 & -0.13 & -0.047 \\
$\mathrm{GLYC}$ & -0.66 & -0.53 & -0.67 & -0.63 & -0.68 & -0.30 \\
$\mathrm{GLYX}$ & 0.43 & 0.58 & 0.47 & -1.2 & 2.1 & 0.076 \\
$\mathrm{HAC}$ & 0.14 & 0.089 & 0.33 & 0.55 & -0.24 & -0.42 \\
MGLY & -0.35 & -0.17 & -0.077 & -0.11 & 0.22 & 0.084 \\
PANs & - & -0.34 & -0.18 & -0.50 & -0.28 & -0.067 \\
$\mathrm{C}_{2+}$ nitrates & -2.8 & -0.68 & 0.77 & 4.4 & 2.4 & 0.02 \\
$\mathrm{C}_{2+}$ hydroperoxides & -0.65 & 0.43 & 0.44 & 0.14 & 1.4 & 2.9 \\
epoxides & $1.7 \mathrm{E}-3$ & 0.32 & 0.21 & 0.11 & 0.28 & 0.38 \\
SOA & 0.17 & 0.23 & 0.082 & -0.10 & 0.17 & 0.023 \\
$\mathrm{C}_{5}$ tetrafunctionals & -12 & -0.048 & -0.21 & -0.074 & -0.64 & 2.2 \\
\hline
\end{tabular}

${ }^{a}$ Includes only non-PAN organonitrates

Table S7 shows the annual global and regional molar product yields from isoprene of species removed from RCIM to create Mini-CIM. We also provide a complete list of the simplifications made to create Mini-CIM below. Naming conventions follow those laid out in Wennberg et al. (2018) and used in RCIM. More details, along with a complete listing of the reactions and species in both RCIM and Mini-CIM, can be found online in the mechanism repository (DOI 10.22002/D1.247)

The following simplifications apply to species that meet the simplification criteria of $<0.1 \%$ yield from isoprene globally and $<1 \%$ yield from isoprene regionally in the Amazon, the Southeast United States, and East China:

- ISOP3CO4OH is replaced with ISOP1OH2OO3CO4OH; because ISOP3CO4OH + OH $=$ ISOP1OH$2 \mathrm{OO} 3 \mathrm{CO} 4 \mathrm{OH}+\mathrm{OH}$ is the only loss process of $\mathrm{ISOP} 3 \mathrm{CO} 4 \mathrm{OH}$, this replacement is $\mathrm{OH}$-neutral.

- The acylperoxy radical of hydroxyethane $\left(\mathrm{HOCH}_{2} \mathrm{C}(\mathrm{O}) \mathrm{OO} \bullet\right)$ is replaced with the peroxyacetyl radical $\left(\mathrm{CH}_{3} \mathrm{C}(\mathrm{O}) \mathrm{OO} \bullet\right)$, and the products of its reactions with $\mathrm{HO}_{2}$ and $\mathrm{NO}_{2}\left(\mathrm{HOCH}_{2} \mathrm{C}(\mathrm{O}) \mathrm{OOH}, \mathrm{HOCH}_{2} \mathrm{C}(\mathrm{O}) \mathrm{OH}\right.$, and $\left.\mathrm{HOCH}_{2} \mathrm{C}(\mathrm{O}) \mathrm{OONO}_{2}\right)$ are removed.

- The acylperoxy radical of nitrooxyethane $\left(\mathrm{O}_{2} \mathrm{NOCH}_{2} \mathrm{C}(\mathrm{O}) \mathrm{OO} \bullet\right)$ is replaced with the peroxyacetyl radical $\left(\mathrm{CH}_{3} \mathrm{C}(\mathrm{O}) \mathrm{OO} \bullet\right)$ plus $\mathrm{NO}_{2}$, and the products of its reactions with $\mathrm{HO}_{2}$ and $\mathrm{NO}_{2}\left(\mathrm{O}_{2} \mathrm{NOCH}_{2} \mathrm{C}(\mathrm{O}) \mathrm{OOH}\right.$, $\mathrm{O}_{2} \mathrm{NOCH}_{2} \mathrm{C}(\mathrm{O}) \mathrm{OH}$, and $\left.\mathrm{O}_{2} \mathrm{NOCH}_{2} \mathrm{C}(\mathrm{O}) \mathrm{OONO}_{2}\right)$ are removed. 
- The three isoprene carbonyl nitrate isomers are lumped into a single species (ICN) representing $70 \%$ ISOP1N4CO, 30\% ISOP1CO4N, and $0 \%$ ISOP $3 \mathrm{CO} 4 \mathrm{~N}$, the proportion in which they are produced in GEOS-Chem simulations; the subsequent reaction rates and products of the single ICN species are scaled according to these proportions.

- ICN3OO (ISOP1OH2OO3CO4N) is removed, as it is no longer produced from IC3N.

- ICN1OO (ISOP1N2OH3OO4CO) and ICN2OO (ISOP1CO2OO3OH4N) are found to undergo rapid H-shifts under almost all ambient conditions (Möller et al., 2019), and are therefore replaced with the H-shift products.

- The acylperoxy radical products of ICN $+\mathrm{OH}$ are lumped into a single species (ICNOO) representing $70 \%$ ICN4OO (ISOP1N4CO4OO) and 30\% ICN5OO (ISOP1CO1OO4N), the proportions in which they are produced in GEOS-Chem simulations; the subsequent reaction rates and products of the single ICNOO species are scaled according to these proportions.

- MVK-derived nitrates are lumped into a single species (MVKN) representing 69\% MVK3N4OH, 29\% MVK3OH4N, $1 \%$ MVK3OOH4N, and $1 \%$ MVK3CO4N, the proportions in which they are produced in GEOS-Chem simulations; the subsequent reaction rates and products of the single MVKN species are scaled according to these proportions.

- MACR1OOH2N3OH is replaced with MACR2N3OH, which has nearly identical subsequent reactions.

- Minor isomers of methacrolein-derived nitrates are lumped into a single species (MACRN) representing $75 \%$ MACR2OH3N, 25\% MACR2OOH3N, and 0\% MACR1OH2N3OH, the proportions in which they are produced in GEOS-Chem simulations; the subsequent reaction rates and products of the single MACRN species are scaled according to these proportions.

- All dinitrates are lumped into a single species (IDN) representing 50\% dihydroxy-dinitrates (IDHDN), $50 \%$ dinitrates retaining a double bond (IDN), $0 \%$ isoprene-hydroxy-hydroperoxy-dinitrates (IHPDN), and $0 \%$ isoprene-carbonyl-hydroxy-dinitrates (ICHDN), the proportions in which they are produced in GEOS-Chem simulations; the subsequent reaction rates and products of the single IDN species are scaled according to these proportions.

- All tri- and tetra-functionalized $\mathrm{C}_{5}$ hydroxynitrates are lumped into a single species (ITHN) representing $90 \%$ isoprene-dihydroxy-hydroperoxy-nitrate (IDHPN), 10\% isoprene-hydroxy-nitrooxy- epoxide (IHNE), $0 \%$ isoprene-hydroxy-dihydroperoxy-nitrates (IHNDP), and $0 \%$ isoprene-hydroxy-hydroperoxynitrooxy-epoxides (IHNPE), the proportions in which they are produced in GEOS-Chem simulations; the subsequent reaction rates and products of the single ITHN species are scaled according to these proportions. Because the hydroxy-nitrates have similar photolytic and $\mathrm{OH}$ loss pathways, this combination minimizes changes to the species' lifetimes.

- Isoprene-carbonyl-nitrooxy-epoxides (ICNE) and isoprene-dihydroxy-carbonyl-nitrates (IDHCN) are replaced with isoprene-carbonyl-hydroxy-hydroperoxy-nitrates (ICHNP), which is renamed as ITCN to reflect the lumped isoprene tri- and tetra-functionalized carbonyl nitrates. Because the carbonylnitrates have similar photolytic and $\mathrm{OH}$ loss pathways, this combination minimizes changes to the species' lifetimes.

- IHNEOO, the peroxy radical from isoprene-hydroxy-nitrooxy-epoxides (IHNE) $+\mathrm{OH}$, is replaced with the peroxy radical from $\mathrm{NO}_{3}$-derived beta-hydroxy nitrates $+\mathrm{OH}$ (IDHNBOO), which reacts similarly.

- The lumped $\beta$-hydroxynitrates from isoprene + NO3 oxidation (IHNB) are combined with the lumped beta-hydroperoxynitrates from isoprene $+\mathrm{NO}_{3}$ oxidation (INPB); the subsequent reaction rates and products of the single INPB species are scaled (33\% IHNB, 67\% INPB) according to the proportions in which they are produced in GEOS-Chem simulations.

- Hydroxy-nitrooxy-methacryloylperoxynitrate (MPANHN) is replaced with methacryloylperoxynitrate $(\mathrm{MPAN})+\mathrm{NO} 2$. 
- The acid (MACR1OH) and peracid (MACR1OOH) from the methacryloylperoxy radical reaction with $\mathrm{HO} 2$ are lumped into a single species (MACR1OOH) representing $75 \% \mathrm{MACR} 1 \mathrm{OOH}$ and $25 \%$ MACR1OH, the proportions in which they are produced in GEOS-Chem simulations; the subsequent reaction rates and products of the single ITHN species are scaled according to these proportions.

- SOA from methylglyoxal (SOAMG) and from HMML (SOAME) are combined, respectively, with SOA from glyoxal (SOAGX) and IEPOX (SOAIE). This simplification applies only to GEOS-Chem, not the gas-phase mechanism found in the online repository.

The following simplifications apply to species that do not meet the yield criteria described above, but are isobaric and have the same loss rates, such that combining them does not affect the species' atmospheric lifetime:

- ISOP1CO4OH and ISOP1OH4CO are lumped into a single $\mathrm{C}_{5}-\delta$-hydroxy-carbonyl species (HC5) representing $65 \%$ ISOP1CO4OH and $35 \%$ ISOP1OH4CO, the proportions in which they are produced in GEOS-Chem simulations; the subsequent reaction rates and products of the single HC5 species are scaled according to these proportions.

- MVKENOL and MCRENOL are lumped into a single $\mathrm{C}_{4}$-enol species (MCRENOL) representing $75 \%$ MCRENOL and 25\% MVKENOL, the proportions in which they are produced in GEOS-Chem simulations; the subsequent reaction rates and products of the single enol species are scaled according to these proportions.

- MACR2OH3CO and MVK3OH4CO have identical reaction pathways, and are therefore lumped into a single $\mathrm{C}_{4}$-hydroxy-dicarbonyl species (MVKHCB).

- MACR2OOH3OH and MACR2OH3OOH are lumped into a single hydroxy-hydroperoxy-methacrolein species (MACRHP) representing 77\% MACR2OOH3OH and 23\% MACR2OH3OOH, the proportions in which they are produced in GEOS-Chem simulations; the subsequent reaction rates and products of the single MACRHP species are scaled according to these proportions.

- MVK3OOH4OH and MVK3OH4OOH are lumped into a single hydroxy-hydroperoxy-MVK species (MVKHP) representing 53\% MVK3OOH4OH and 47\% MVK3OH4OOH, the proportions in which they are produced in GEOS-Chem simulations; the subsequent reaction rates and products of the single MVKHP species are scaled according to these proportions. 
Table S7: Annual mean molar yields (\%) from isoprene of species removed from the simplified mechanism ${ }^{a}$

\begin{tabular}{|c|c|c|c|c|}
\hline species & global & Amazon & SE USA & E China \\
\hline $\mathrm{HOCH}_{2} \mathrm{CO}_{2} \mathrm{H}$ & $1.7 \mathrm{E}-4$ & $1.9 \mathrm{E}-6$ & $1.8 \mathrm{E}-5$ & $1.2 \mathrm{E}-5$ \\
\hline $\mathrm{HOCH}_{2} \mathrm{CO}_{3} \mathrm{H}$ & $3.3 \mathrm{E}-4$ & $2.4 \mathrm{E}-6$ & $3.1 \mathrm{E}-5$ & $2.1 \mathrm{E}-5$ \\
\hline $\mathrm{O}_{2} \mathrm{NOCH}_{2} \mathrm{CO}_{2} \mathrm{H}$ & $5.8 \mathrm{E}-4$ & $2.0 \mathrm{E}-5$ & $3.7 \mathrm{E}-4$ & $5.6 \mathrm{E}-4$ \\
\hline $\mathrm{O}_{2} \mathrm{NOCH}_{2} \mathrm{CO}_{3} \mathrm{H}$ & $9.3 \mathrm{E}-4$ & $2.5 \mathrm{E}-5$ & $6.2 \mathrm{E}-4$ & $9.3 \mathrm{E}-4$ \\
\hline $\mathrm{O}_{2} \mathrm{NOCH}_{2} \mathrm{CO}_{3} \mathrm{NO}_{2}$ & 0.012 & $2.6 \mathrm{E}-4$ & 0.017 & 0.080 \\
\hline $\mathrm{HOCH}_{2} \mathrm{CO}_{3} \mathrm{NO}_{2}$ & $8.7 \mathrm{E}-4$ & $1.1 \mathrm{E}-5$ & $6.7 \mathrm{E}-4$ & $9.9 \mathrm{E}-4$ \\
\hline MPANHN & 0.018 & $1.5 \mathrm{E}-3$ & 0.037 & 0.049 \\
\hline MVK3OOH4N & $6.9 \mathrm{E}-3$ & $5.6 \mathrm{E}-4$ & 0.013 & 0.023 \\
\hline MVK3CO4N & $5.2 \mathrm{E}-3$ & $1.7 \mathrm{E}-4$ & $7.6 \mathrm{E}-3$ & 0.011 \\
\hline MACR2OOH3N & 0.023 & $1.3 \mathrm{E}-3$ & 0.045 & 0.059 \\
\hline MACR1OH2N3OH & $2.2 \mathrm{E}-3$ & $7.3 \mathrm{E}-4$ & $1.5 \mathrm{E}-3$ & 7.3E-4 \\
\hline MACR1OOH2N3OH & $2.5 \mathrm{E}-3$ & $6.8 \mathrm{E}-4$ & $2.1 \mathrm{E}-3$ & $1.2 \mathrm{E}-3$ \\
\hline ISOP3CO4OH & 0.069 & 0.037 & 0.059 & 0.036 \\
\hline ISOP1CO4N & 0.088 & $8.2 \mathrm{E}-3$ & 0.21 & 0.32 \\
\hline ISOP $3 \mathrm{CO} 4 \mathrm{~N}$ & $9.1 \mathrm{E}-3$ & $7.8 \mathrm{E}-4$ & 0.024 & 0.024 \\
\hline dinitrooxy-isoprene & 0.035 & $4.0 \mathrm{E}-3$ & 0.092 & 0.20 \\
\hline nighttime $\beta$-hydroxynitrates & 0.053 & $4.9 \mathrm{E}-3$ & 0.13 & 0.13 \\
\hline $\mathrm{C}_{5}$ dihydroxy-dinitrates & 0.035 & $2.1 \mathrm{E}-3$ & 0.068 & 0.17 \\
\hline $\mathrm{C}_{5}$ hydroxy-hydroperoxy-dinitrates & $2.1 \mathrm{E}-3$ & $6.8 \mathrm{E}-5$ & $2.9 \mathrm{E}-3$ & $1.3 \mathrm{E}-3$ \\
\hline $\mathrm{C}_{5}$ carbonyl-hydroxy-dinitrates & $1.3 \mathrm{E}-3$ & $3.7 \mathrm{E}-6$ & $3.9 \mathrm{E}-4$ & $8.0 \mathrm{E}-4$ \\
\hline $\mathrm{C}_{5}$ hydroxy-nitrooxy-epoxides & 0.027 & $2.1 \mathrm{E}-3$ & 0.037 & 0.013 \\
\hline $\mathrm{C}_{5}$ hydroxy-nitrooxy-dihydroperoxides & $5.4 \mathrm{E}-3$ & $3.9 \mathrm{E}-4$ & $4.7 \mathrm{E}-3$ & $1.0 \mathrm{E}-3$ \\
\hline $\mathrm{C}_{5}$ hydroxy-nitrooxy-hydroperoxy-epoxides & $2.0-\mathrm{E}-3$ & $2.5 \mathrm{E}-4$ & $3.3 \mathrm{E}-3$ & $8.0 \mathrm{E}-4$ \\
\hline $\mathrm{C}_{5}$ carbonyl-nitrooxy-epoxides & $1.4 \mathrm{E}-3$ & $2.5 \mathrm{E}-5$ & $6.1 \mathrm{E}-4$ & $2.6 \mathrm{E}-4$ \\
\hline $\mathrm{C}_{5}$ carbonyl-dihydroxy-nitrates & 0.011 & $1.5 \mathrm{E}-4$ & $3.9 \mathrm{E}-3$ & 7.6E-3 \\
\hline $\mathrm{MVK}^{2} \mathrm{OH} 4 \mathrm{~N}^{b}$ & 0.17 & 0.015 & 0.21 & 0.48 \\
\hline ISOP1OH4CO ${ }^{b}$ & 0.31 & 0.24 & 0.38 & 0.57 \\
\hline $\mathrm{MVK} \mathrm{OH} 4 \mathrm{OOH}^{b}$ & 2.5 & 1.1 & 1.3 & 1.1 \\
\hline MVKENOL $^{b}$ & 0.37 & 0.65 & 0.22 & 0.12 \\
\hline $\mathrm{MACR} 2 \mathrm{OH} 3 \mathrm{CO}^{b}$ & 0.25 & 0.026 & 0.12 & 0.13 \\
\hline 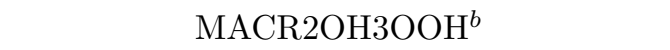 & 0.24 & 0.13 & 0.20 & 0.24 \\
\hline $\mathrm{MACR} 1 \mathrm{OH}{ }^{b}$ & 0.36 & 0.25 & 0.14 & 0.064 \\
\hline SOA from HMML/MAE ${ }^{c}$ & 0.023 & $2.6 \mathrm{E}-3$ & $7.9 \mathrm{E}-3$ & 0.030 \\
\hline SOA from methylglyoxal ${ }^{c}$ & $2.1 \mathrm{E}-3$ & $2.0 \mathrm{E}-3$ & $2.1 \mathrm{E}-3$ & 0.015 \\
\hline
\end{tabular}

${ }^{a}$ Species names are derived from Wennberg et al. (2018) and the mechanism posted in the online repository; ${ }^{b}$ While these species' yields exceed the threshold set for exclusion, their lifetimes and loss pathways are sufficiently similar to those of other species in the mechanism to facilitate their combination (see text); ${ }^{c}$ These simplification applies only to GEOS-Chem, not the gas-phase mechanism found in the online repository. 


\section{References}

Arey, J., Aschmann, S. M., Kwok, E. S., and Atkinson, R.: Alkyl nitrate, hydroxyalkyl nitrate, and hydroxycarbonyl formation from the NOx-air photooxidations of C5-C8 n-alkanes, J. Phys. Chem. A, 105, 1020-1027, 2001.

Carter, W. P. L. and Atkinson, R.: Atmospheric chemistry of alkanes, J. Atmos. Chem., 3, 377-405, https://doi.org/10.1007/BF00122525, 1985.

Carter, W. P. L. and Atkinson, R.: Alkyl nitrate formation from the atmospheric photoxidation of alkanes: A revised estimation method, J. Atmos. Chem., 8, 165173, 1989.

Crounse, J. D., Paulot, F., Kjaergaard, H. G., and Wennberg, P. O.: Peroxy radical isomerization in the oxidation of isoprene, Phys. Chem. Chem. Phys., 13, 13607-13613, 2011.

Jacobs, M. I., Burke, W. J., and Elrod, M. J.: Kinetics of the reactions of isoprene-derived hydroxynitrates: Gas phase epoxide formation and solution phase hydrolysis, Atmos. Chem. Phys., 14, 8933-8946, https://doi.org/10.5194/acp-14-8933-2014, 2014.

Jenkin, M. E., Young, J. C., and Rickard, A. R.: The MCM v3.3.1 degradation scheme for isoprene, Atmos. Chem. Phys., 15, 11 433-11 459, https://doi.org/10.5194/acp-15-11433-2015, 2015.

Mao, J., Paulot, F., Jacob, D. J., Cohen, R. C., Crounse, J. D., Wennberg, P. O., Keller, C. A., Hudman, R. C., Barkley, M. P., and Horowitz, L. W.: Ozone and organic nitrates over the eastern United States: Sensitivity to isoprene chemistry, J. Geophys. Res., 118, 11 256-11 268, 2013.

Möller, K. H., Bates, K. H., and Kjaergaard, H. G.: The importance of peroxy radical hydrogenshift reactions in atmospheric isoprene oxidation, J. Phys. Chem. A, 123, 920-932, https://doi.org/ 10.1021/acs.jpca.8b10432, 2019.

Paulot, F., Crounse, J. D., Kjaergaard, H. G., Kroll, J. H., Seinfeld, J. H., and Wennberg, P. O.: Isoprene photooxidation: new insights into the production of acids and organic nitrates, Atmos. Chem. Phys., 9, 1479-1501, 2009.

Peeters, J. and Nguyen, T. L.: Unusually fast 1,6-H shifts of enolic hydrogens in peroxy radicals: formation of the first-generation C2 and C3 carbonyls in the oxidation of isoprene, J. Phys. Chem. A, 116, 6134-6141, https://doi.org/10.1021/jp211447q, 2012.

Peeters, J., Muller, J. F., Stavrakou, T., and Nguyen, V. S.: Hydroxyl radical recycling in isoprene oxidation driven by hydrogen bonding and hydrogen tunneling: The upgraded LIM1 mechanism, J Phys. Chem. A, 118, 8625-8643, https://doi.org/10.1021/jp5033146, 2014.

Praske, E., Otkjær, R. V., Crounse, J. D., Hethcox, J. C., Stoltz, B. M., Kjaergaard, H. G., and Wennberg, P. O.: Atmospheric autoxidation is increasingly important in urban and suburban North America, Proc. Natl. Acad. Sci., 115, 64-69, https://doi.org/10.1073/pnas.1715540115, 2018.

Schwantes, R. H., Teng, A. P., Nguyen, T. B., Coggon, M. M., Crounse, J. D., Clair, J. M. S., Zhang, X., Schilling, K. A., Seinfeld, J. H., and Wennberg, P. O.: Isoprene NO3 oxidation products from the RO2 + HO2 pathway, J. Phys. Chem. A, 119, $10158-10$ 171, https://doi.org/10.1021/acs.jpca.5b06355, 2015.

Wennberg, P. O., Bates, K. H., Crounse, J. D., Dodson, L. G., McVay, R. C., Mertens, L. A., Nguyen, T. B., Praske, E., Schwantes, R. H., Smarte, M. D., St Clair, J. M., Teng, A. P., Zhang, X., and Seinfeld, J. H.: Gas-phase reactions of isoprene and its major oxidation products, Chem. Rev., 118, 3337-3390, https://doi.org/10.1021/acs.chemrev.7b00439, 2018. 